ARTICLE

\title{
Directing reaction pathways via in situ control of active site geometries in PdAu single-atom alloy catalysts
}

Mengyao Ouyang1, Konstantinos G. Papanikolaou (10 2, Alexey Boubnov ${ }^{3}$, Adam S. Hoffman (1) ${ }^{3}$, Georgios Giannakakis ${ }^{1}$, Simon R. Bare (10) ${ }^{3}$, Michail Stamatakis ${ }^{2}$, Maria Flytzani-Stephanopoulos (1) ${ }^{1} \&$ E. Charles H. Sykes (D) 4 凶

The atomic scale structure of the active sites in heterogeneous catalysts is central to their reactivity and selectivity. Therefore, understanding active site stability and evolution under different reaction conditions is key to the design of efficient and robust catalysts. Herein we describe theoretical calculations which predict that carbon monoxide can be used to stabilize different active site geometries in bimetallic alloys and then demonstrate experimentally that the same PdAu bimetallic catalyst can be transitioned between a single-atom alloy and a Pd cluster phase. Each state of the catalyst exhibits distinct selectivity for the dehydrogenation of ethanol reaction with the single-atom alloy phase exhibiting high selectivity to acetaldehyde and hydrogen versus a range of products from Pd clusters. First-principles based Monte Carlo calculations explain the origin of this active site ensemble size tuning effect, and this work serves as a demonstration of what should be a general phenomenon that enables in situ control over catalyst selectivity.

\footnotetext{
${ }^{1}$ Department of Chemical and Biological Engineering, Tufts University, Medford, MA, USA. ${ }^{2}$ Thomas Young Centre and Department of Chemical Engineering, University College London, London, UK. ${ }^{3}$ Stanford Synchrotron Radiation Light Source, SLAC National Accelerator Laboratory, Menlo Park, CA, USA. ${ }^{4}$ Department of Chemistry, Tufts University, Medford, MA, USA. ${ }^{凶}$ email: charles.sykes@tufts.edu
} 
B imetallic catalysts often exhibit enhanced catalytic performance compared to their monometallic counterparts and are widely used in many chemical transformations including reforming ${ }^{1,2}$, coupling $^{3}$, pollution control $^{4,5}$, and oxidation ${ }^{6,7}$ reactions. The specific reactivity of bimetallic catalysts is generally explained via ensemble (geometric) and/or ligand (electronic) effects that lead to enhanced reactivity and/or selectivity ${ }^{8-10}$. An extreme example of the ensemble effect is utilized in single-atom alloy (SAA) catalysts, in which a more reactive element is atomically dispersed in a less active host metal ${ }^{11,12}$. Usually, platinum group metals (PGM) are dispersed as isolated single atoms in coinage metals $(\mathrm{Cu}, \mathrm{Au}, \mathrm{Ag})$ and they exhibit enhanced reactivity/selectivity and stability over their monometallic counterparts $^{13}$. For example, the PtCu SAA is more efficient at alkane dehydrogenation than $\mathrm{Cu}$ while avoiding the coking that occurs on catalysts with extended $\mathrm{Pt}$ clusters ${ }^{14}$. This $\mathrm{PtCu} / \mathrm{SiO}_{2} \mathrm{SAA}$ is also highly selective for the hydrogenation of 1,3-butadiene to butene $^{15}$ and acetylene to ethylene ${ }^{14}$ via a mechanism in which $\mathrm{H}_{2}$ dissociates at isolated $\mathrm{Pt}$ atom sites and the $\mathrm{H}$ atoms spill over to $\mathrm{Cu}$, where the selective hydrogenation occurs. In contrast, $\mathrm{Pt}$ clusters lead to over-hydrogenation and deactivation. For some other reactions, clusters of the catalytically active metal atom are needed to activate chemical bonds and obtain the desired products. For example, contiguous $\mathrm{Pd}$ sites are necessary for $\mathrm{O}_{2}$ activation in the $\mathrm{CO}$ oxidation reaction, whereas single $\mathrm{Pd}$ atoms in $\mathrm{Au}$ are inactive for this reaction ${ }^{16,17}$. Also, Pd nanoparticles (NPs) are needed for the methane oxidation reaction, and the decomposition of the NPs into single Pd atoms at high temperatures leads to a drop in reactivity ${ }^{18}$. Furthermore, Ni and $\mathrm{Pt}$ clusters are required for the complete hydrogenation of ethylene to ethane, as this reaction does not take place on highly dilute $\mathrm{NiCu}$ alloys ${ }^{19}$ or the PtCu SAA ${ }^{14}$. For alcohol conversion, which is the focus of this study, isolated $\mathrm{Ni}$ atoms are not able to break the $\mathrm{C}-\mathrm{C}$ bond of ethanol ${ }^{20,21}$, therefore Ni clusters are needed in the cracking process or hydrogenolysis reactions ${ }^{22}$. Together, these findings illustrate that the atomic-scale structure of the active sites in bimetallic catalysts has a critical effect on their chemical reactivity and selectivity. Therefore, in situ control of the structure of the active sites in bimetallic catalysts should offer a way to tune reaction networks and achieve efficient conversion to the desired products.

Catalysts are known to dynamically restructure under reactive atmospheres ${ }^{23-29}$. In metal alloy catalysts, the driving force for such changes is often derived from differences in the binding strength of an adsorbate to the different metallic components of the alloy. For example, $\mathrm{Wu}$ et al. ${ }^{23}$ reported that the CO oxidation process induced the reconstruction of CoPd bimetallic NPs, forming $\mathrm{CoO}_{\mathrm{x}}$ species on the surface which promoted $\mathrm{CO}$ oxidation. McCue et al. ${ }^{30}$ reported on $\mathrm{PdCu}$ alloys for which $\mathrm{CO}$ treatment led to $\mathrm{Pd}$ atoms aggregating on the surface resulting in an improved activity for the acetylene hydrogenation reaction. Gao et al. ${ }^{31}$ reported the formation of contiguous Pd sites on an $\mathrm{Au}(100)$ surface at $\mathrm{CO}$ pressures higher than 0.1 Torr, which leads to an increased rate of $\mathrm{CO}_{2}$ formation. Considering these findings, understanding how the active sites in bimetallic catalysts reconfigure in response to changes in gas-phase composition is a critical step in unraveling intrinsic reaction mechanisms and ultimately controlling reaction pathways in situ.

While many bimetallic catalysts are difficult to model accurately, SAA catalysts with their simple structure in which the dopant atom substitutes a host metal atom, are more amenable to accurate modeling that includes the effect of restructuring $26,28,32-44$. Theoretical studies on SAAs by Darby et al. ${ }^{42}$ and Papanikolaou et al. ${ }^{43,44}$ predicted that the surface coverage of $\mathrm{CO}$ has an impact on the structure of the PGM ensembles present on the surface. Specifically, it was found that at different CO coverages (a variable that can be experimentally controlled), certain bimetallic catalysts exhibit stable dimers, trimers, or larger clusters in the surface. These theoretical studies, therefore, suggest a method for manipulating the structure of the active sites of a bimetallic catalyst in situ.

Here, we show the translation of these theoretical results to working catalysts and probe this effect experimentally using $\mathrm{PdAu}$ SAA nanoparticle catalysts supported on $\mathrm{SiO}_{2}$. Using in situ CO-DRIFTS, we monitor the structure of Pd ensembles and demonstrate that their structure can be reversibly tuned from isolated atoms to clusters by changing CO partial pressure as a function of temperature. These experimental observations are further rationalized using on-lattice Monte Carlo (MC) simulations parametrized by density functional theory (DFT), which show how the pressure of CO and temperature affect the geometry of the Pd ensembles. Furthermore, we demonstrate how in situ control of the active sites with $\mathrm{CO}$ can be used to transition the catalyst from a SAA phase that is selective to acetaldehyde and hydrogen to a Pd cluster phase which leads to the formation of $\mathrm{CO}$, ethyl acetate, and $\mathrm{CH}_{4}$ as byproducts in the ethanol dehydrogenation (EDH) reaction. This should be a somewhat general method for in situ control of catalyst selectivity that can be predicted a priori by DFT and MC simulations.

\section{Results and discussion}

Predicted effect of $\mathrm{CO}$ on Pd segregation and aggregation. A primary consideration for designing a working SAA catalyst is whether the catalytically active atoms will be stable in the surface layer of the nanoparticle and accessible to the reactants. Our theoretical calculations demonstrate that, under vacuum conditions, there is an enthalpic preference for $\mathrm{Pd}$ atoms to reside in the bulk of the Au host $\left(\Delta E_{\mathrm{seg}}=-0.36 \mathrm{eV}\right)$ as seen in Fig. 1a due to the higher surface energy of $\mathrm{Pd}$ compared to that of $\mathrm{Au}^{45,46}$. In contrast, in the presence of $\mathrm{CO}$, the strong $\mathrm{Pd}-\mathrm{CO}$ bond leads to $\mathrm{Pd}$ atoms exhibiting higher thermodynamic stability in the surface of the bimetallic alloy $\left(\Delta E_{\mathrm{seg}}^{\mathrm{CO}}=+0.48 \mathrm{eV}\right)$ (Fig. 1b), which drives $\mathrm{CO}$-induced surface segregation.

In addition to surface segregation, our results suggest that $\mathrm{CO}$ is capable of inducing the surface aggregation of $\mathrm{Pd}$ atoms, thereby changing the size of the Pd ensembles at the catalyst surface ${ }^{42-44}$. Specifically, in the absence of $\mathrm{CO}$, we compute positive aggregation energies for both Pd-Pd dimers $\left(\Delta E_{\mathrm{agg}}=+0.07 \mathrm{eV}\right)$ and $\mathrm{Pd}$ trimers $\left(\Delta E_{\mathrm{agg}}=+0.18 \mathrm{eV}\right)$. These values indicate that there is a thermodynamic preference for the Pd atoms to be isolated from one another in the PdAu surface (Fig. 1c, d) - (see "Methods" for the definition of the pertinent energy differences). Furthermore, our calculations show that the formation of the aforementioned $\mathrm{Pd}$ aggregates is favored at relatively low $\mathrm{CO}$ dopant fractional coverages (Fig. 1e, f) ${ }^{43}$. This is because the most stable adsorption sites for a single $\mathrm{CO}$ molecule are bridge or threefold hollow sites between adjacent dopant atoms leading to the formation of Pd dimers and trimers in the catalytic surface.

In contrast, at higher $\mathrm{CO}$ coverages, the $\mathrm{CO}$ adsorption geometries on dopant dimers or trimers are tilted away from one another. These repulsive CO-CO lateral interactions ${ }^{42,43,47,48}$ are expected to promote Pd dispersion back to single atoms (Fig. 1e, f). Therefore, it appears that $\mathrm{CO}$ can be used to stabilize the active site ensemble size in bimetallic alloys.

Regarding the binding of CO on the most stable adsorption site of the Pd ensembles (i.e., monomers, dimers, and trimers), we find that the CO-binding strength increases with increasing size of the Pd cluster (Fig. 1g); therefore, Pd dimers and trimers are expected to exhibit higher reactivity than isolated Pd atoms. Such a trend can be rationalized by the position of the $d$ band center $\left(\varepsilon_{\mathrm{d}}\right)$ of the $d$ states of the atoms that comprise the adsorption site (Fig. $1 \mathrm{~g}$ ) ${ }^{49}$. We note that $\varepsilon_{\mathrm{d}}$ shifts to less negative 
(a)

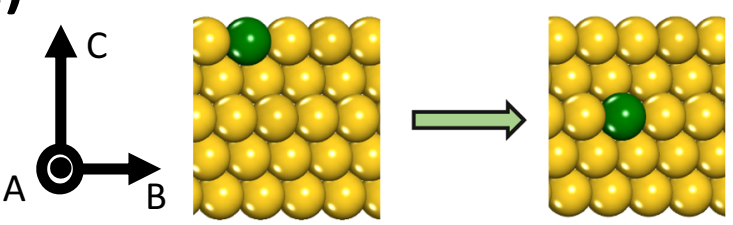

(b)

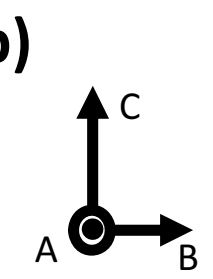

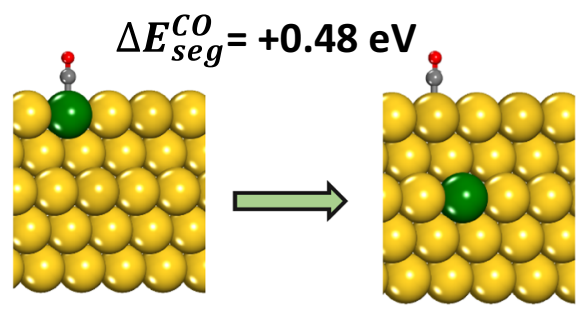

(c)

$\Delta E_{\text {agg }}=+\mathbf{0 . 0 7} \mathrm{eV}$
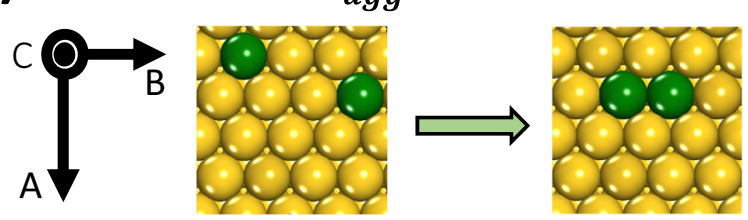

(e)

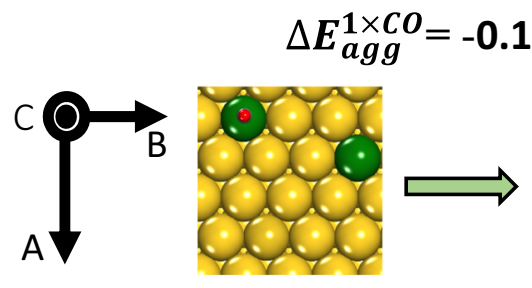

$-0.15 \mathrm{eV}$
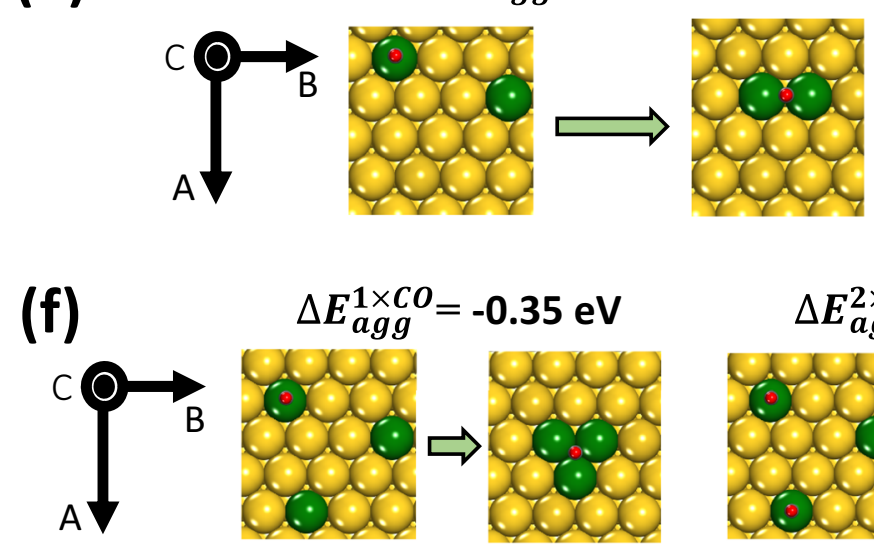

(d)
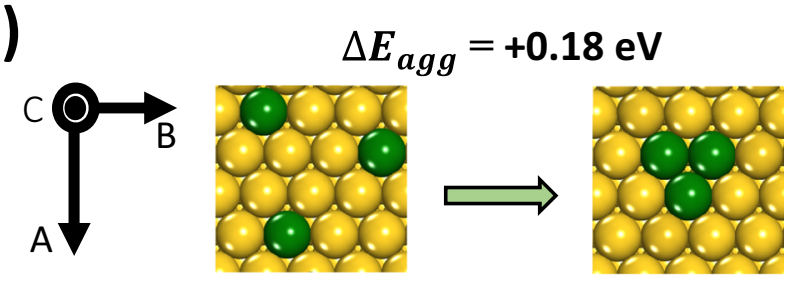

$$
\Delta E_{a g g}^{2 \times C o}=+0.12 \mathrm{eV}
$$
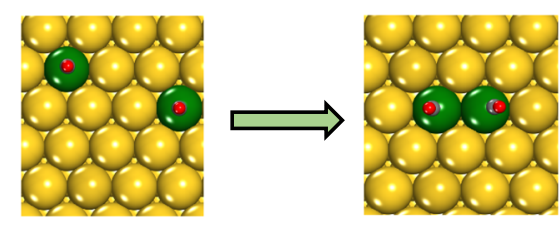

(g)
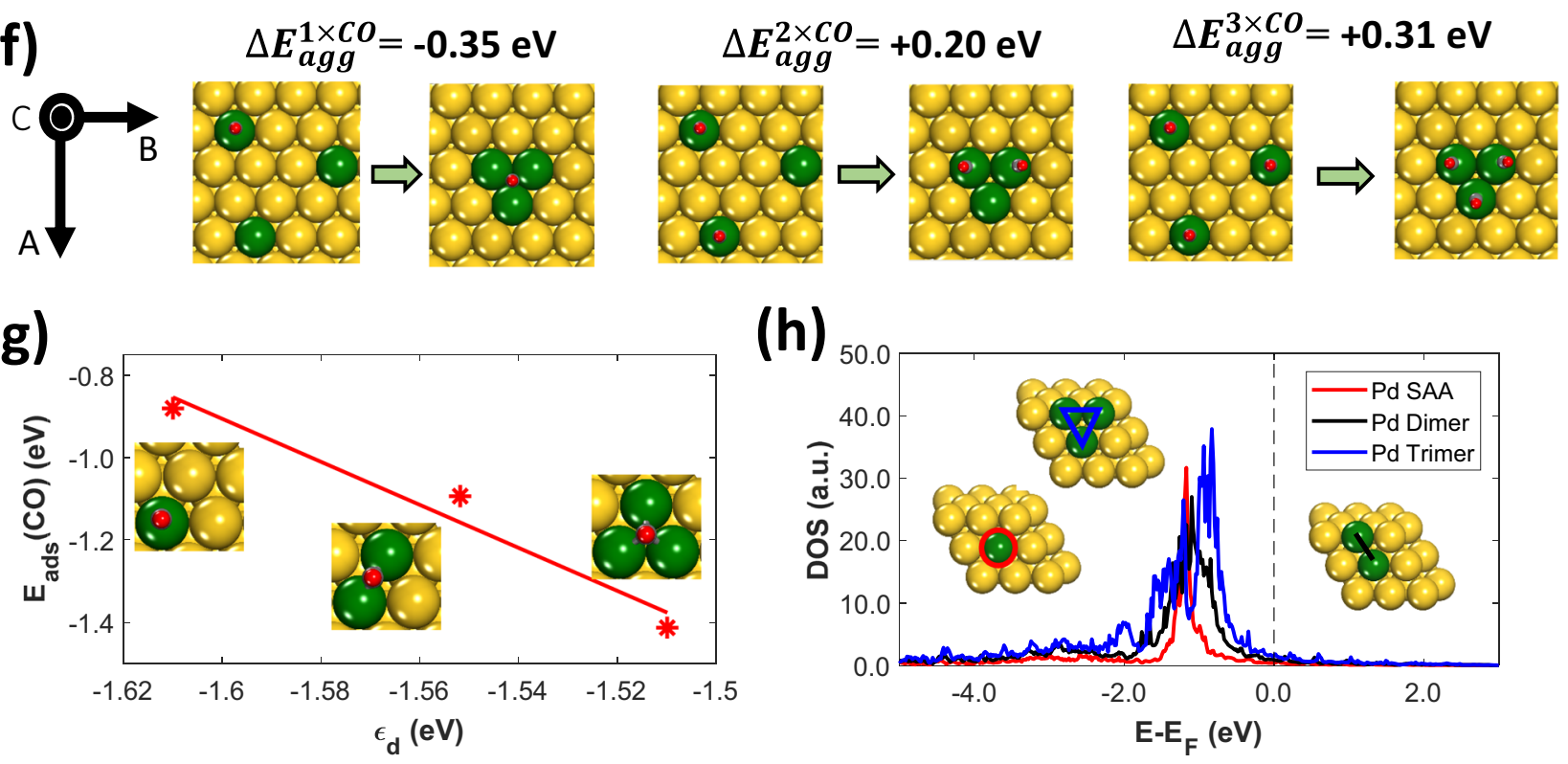

(h)

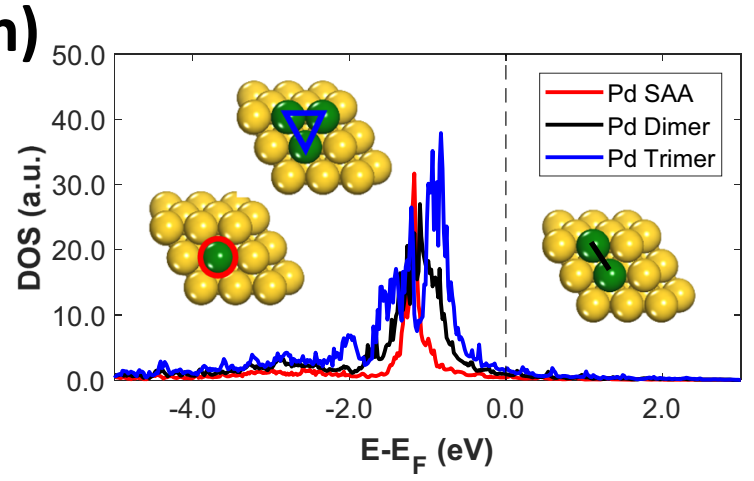

Fig. 1 Predicted effect of $\mathbf{C O}$ on Pd segregation and aggregation. Initial and final states for (a) Pd segregation; $\mathbf{b}$ CO-induced Pd segregation; $\mathbf{c}$ Pd-Pd dimer aggregation; $\mathbf{d}$ Pd trimer aggregation; e CO-induced Pd-Pd dimer aggregation at different CO fractional coverages; and $\mathbf{f}$ CO-induced Pd trimer aggregation at different $\mathrm{CO}$ fractional coverages. Values of segregation or aggregation energies are shown on the top of each panel. The given segregation energies in panels (a) and (b) are per Pd atom; negative segregation energy $\left(\Delta E_{\text {seg }}\right)$ values indicate an enthalpic preference for $\mathrm{Pd}$ to segregate into the bulk, while positive values indicate a preference for Pd segregation to the surface layer. The reported aggregation energies are given relative to the energy of a SAA; negative aggregation energy $\left(\Delta E_{\text {agg }}\right)$ values imply a preference for Pd atoms to cluster into dimers, whereas when $\Delta E_{\text {agg }}>0$ there is a

thermodynamic preference for the SAA phase (i.e., isolated Pd atoms in the Au surface). Panels ( $\mathbf{g}$ ) and (h) show a linear correlation between the CO adsorption energy $\left(E_{\mathrm{ads}}(\mathrm{CO})\right)$ and the $d$ band center of the $d$ states of the Pd atoms that comprise the adsorption site, and $d$ density of states (DOS) plots in which the DOS are projected onto the same atoms, respectively. Au, Pd, C, and $\mathrm{O}$ atoms are shown in yellow, green, gray and red, respectively. The $\mathrm{Pd}$ atoms onto which the $d$ DOS are projected in panel (h) are highlighted in the colors of the corresponding DOS plots. In the schematics of the axes, the symbol $\bigcirc$ denotes an arrow pointing from the page toward the reader.

values as the size of the Pd clusters increase and that $\varepsilon_{d}$ scales linearly with $E_{\text {ads }}(\mathrm{CO})$ (Fig. $1 \mathrm{~g}$ ). This observed shift of $\varepsilon_{\mathrm{d}}$ is the result of the $d$ density of states (DOS) for dimers and trimers being closer to the Fermi level compared to $\mathrm{Pd}$ single atoms
(Fig. 1h), thereby explaining not only the strong $\mathrm{Pd}$ cluster-adsorbate interactions, but also why the cluster samples have higher reactivity than the SAA, albeit at the cost of selectivity $17,50,51$. 
(a)

Sequential

Reduction
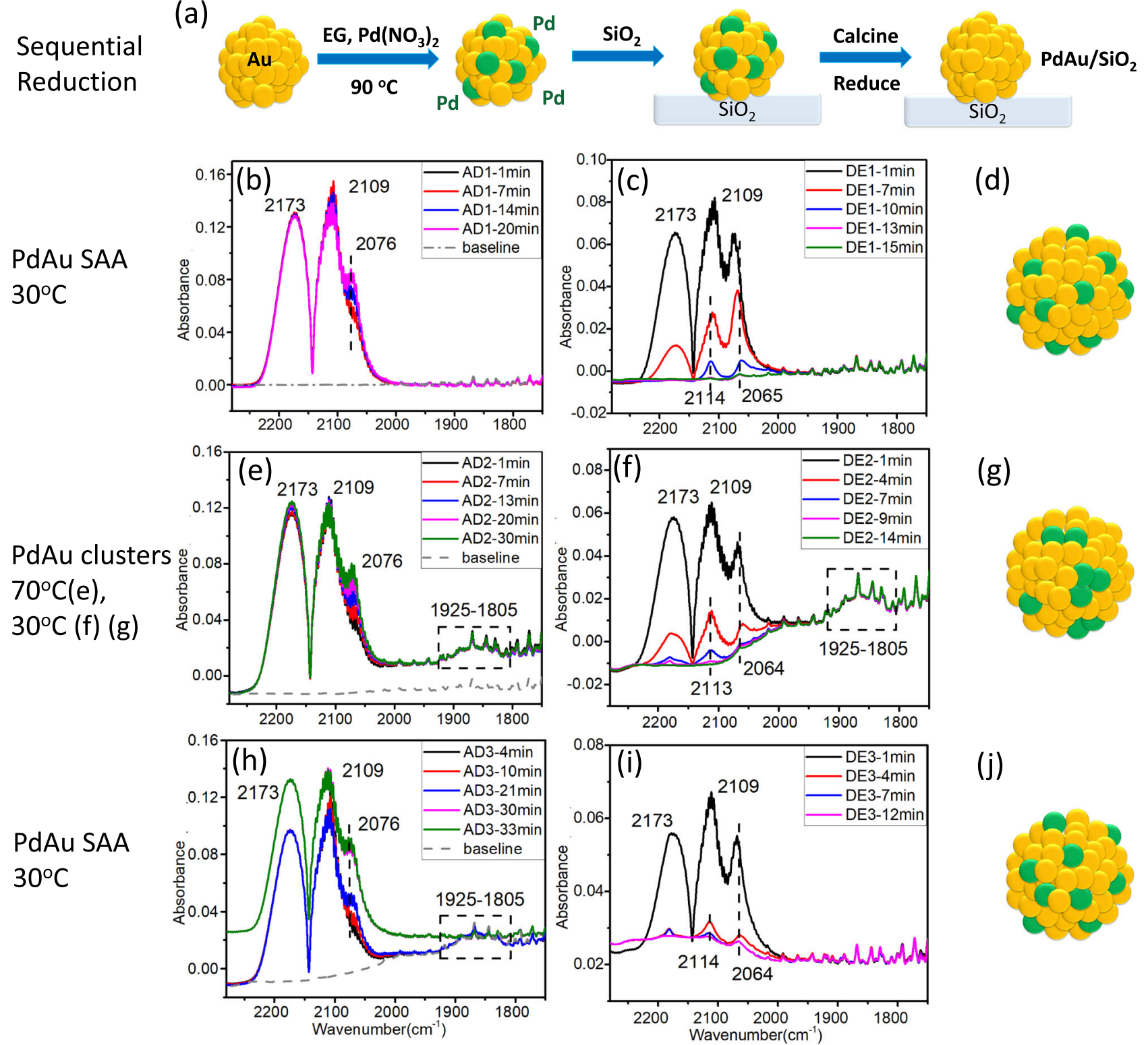

(j)

Fig. $\mathbf{2}$ In situ IR data of Pd clustering and redispersion induced by CO. a Schematic illustration of $\mathrm{PdAu} / \mathrm{SiO}_{2}$ synthesis in which the final reduction step leads to migration of Pd to the interior of the NPs. CO-DRIFTS results and proposed structures of a $\mathrm{Pd}_{0.02} \mathrm{Au}_{0.98} / \mathrm{SiO}_{2}$ sample at $30{ }^{\circ} \mathrm{C}(\mathbf{b}-\mathbf{d}), 70{ }^{\circ} \mathrm{C}(\mathbf{e})$, $30{ }^{\circ} \mathrm{C}(\mathbf{f}, \mathbf{g}), 30^{\circ} \mathrm{C}(\mathbf{h}-\mathbf{j})$ during $10 \% \mathrm{CO} /$ He adsorption $(A D)\left(P_{C O}=0.1\right.$ bar) and desorption (DE) process. Prior to the experiment, the sample was reduced at $200^{\circ} \mathrm{C}$ in $5 \% \mathrm{H}_{2} / \mathrm{He}$ for $1 \mathrm{~h}$ in situ. The labels in the upper right panels indicate the $\mathrm{CO}$ adsorption (AD), and desorption processes (DE) via He purge.

In situ IR of Pd clustering and redispersion induced by CO. Inspired by these theoretical results, we synthesized and tested $\mathrm{PdAu} / \mathrm{SiO}_{2}$ bimetallic catalysts. $\mathrm{Pd}_{0.02} \mathrm{Au}_{0.98} \mathrm{NPs}$ with a $\mathrm{Pd} / \mathrm{Au}$ atomic ratio of $1 / 49$ and an average diameter of $7.6 \pm 1.9 \mathrm{~nm}^{52,53}$ were prepared by the sequential reduction method and then supported on $\mathrm{SiO}_{2}$ (Fig. 2a and Supplementary Table S1). Our DFT calculations indicate that after the calcination and reduction process which removes all surface-bound species, the most thermodynamically stable state of Pd is in the bulk of the Au NPs (Fig. 1a). We used in situ CO-DRIFT spectroscopy to monitor the surface structure of the $\mathrm{Pd}_{0.02} \mathrm{Au}_{0.98} / \mathrm{SiO}_{2}$ catalysts and their dynamic response to $\mathrm{CO}$ in flow mode. In these experiments, $\mathrm{CO}$ induces restructuring of $\mathrm{Pd}$ ensembles in the surface of $\mathrm{Pd}_{0.02} \mathrm{Au}_{0.98} \mathrm{NPs}$, while simultaneously acting as the probe of the adsorption site types.

Figure 2 summarizes the synthesis and the IR characterization data, in which the as-synthesized $\mathrm{Pd}_{0.02} \mathrm{Au}_{0.98} / \mathrm{SiO}_{2}$ catalysts are first reduced in $\mathrm{H}_{2}$ at $200{ }^{\circ} \mathrm{C}$ followed by $\mathrm{CO}$ adsorption (denoted as $\mathrm{AD}$ ) and desorption (denoted as $\mathrm{DE}$ ) in sequential temperature steps. To examine the effect of the $\mathrm{H}_{2}$ reduction treatment on $\mathrm{Pd}$ segregation to the surface, we computed the corresponding segregation energies. We find $\Delta E_{\text {seg }}^{H}=-0.12 \mathrm{eV}$ and $\Delta E_{\mathrm{seg}}^{\mathrm{H}_{2}}=-0.15 \mathrm{eV}$, which demonstrates the ineffectiveness of hydrogen $\left(\mathrm{H}\right.$ and $\left.\mathrm{H}_{2}\right)$ at stabilizing $\mathrm{Pd}$ atoms originally present in the bulk in the surface ${ }^{54}$. Therefore, we expect that very little, if any, Pd segregation to the catalyst surface should occur prior to exposure to $\mathrm{CO}^{54}$. During $\mathrm{CO}$ adsorption at $30^{\circ} \mathrm{C}$ (Fig. $2 \mathrm{~b}$ ), the two adsorption bands at $2173 \mathrm{~cm}^{-1}$ and $2109 \mathrm{~cm}^{-1}$ arise from the $\mathrm{R}$ and $\mathrm{P}$ branches of gaseous $\mathrm{CO}^{55}$. The shape of the peak at $2109 \mathrm{~cm}^{-1}$ is different from the usual $\mathrm{P}$ branch of gaseous CO peak, which results from its overlap with $\mathrm{CO}$ adsorbed on $\mathrm{Au}$ atop sites ${ }^{56,57}$. A shoulder at $2076 \mathrm{~cm}^{-1}$ forms and increases in intensity during the $\mathrm{CO}$ adsorption process (AD1-1min to AD1$20 \mathrm{~min})$. This peak is attributed to CO-bound atop isolated Pd 
sites at high CO coverage ${ }^{17,31,58}$. The increase of this peak intensity with time indicates that after $\mathrm{H}_{2}$ reduction the $\mathrm{Pd}$ resides in the NP bulk and that $\mathrm{CO}$ induces the migration of $\mathrm{Pd}$ atoms to the surface because $\mathrm{CO}$ binds to $\mathrm{Pd}$ stronger than to $\mathrm{Au}^{31,59}$, in agreement with our DFT calculations. During the adsorption process, the intensity of the peak at $2109 \mathrm{~cm}^{-1}$ decreases, suggesting a decrease of $\mathrm{Au}$ atoms on the surface of the NP as they are replaced with Pd atoms. During the desorption process at $30^{\circ} \mathrm{C}$ via helium purge (Fig. $2 \mathrm{c}$ ), the gaseous $\mathrm{CO}$ signal decreases in intensity as gas-phase CO is flushed from the system, and two peaks at $2114 \mathrm{~cm}^{-1}$ and $2065 \mathrm{~cm}^{-1}$ are observed and assigned to atop $\mathrm{CO}$ adsorption on $\mathrm{Au}^{56,57}$ and isolated $\mathrm{Pd}$ sites $^{17,31,58}$, respectively. There are no observable bands associated with bridge-bound CO, indicating that under these conditions, Pd is atomically dispersed in the surface of Au NPs (Fig. 2d). The shift of the atop CO peak on isolated Pd from $2076 \mathrm{~cm}^{-1}$ to $2065 \mathrm{~cm}^{-1}$ is attributed to decreased competition for metal d-electrons back-donated into the CO $2 \pi^{*}$ orbital or decreased dipole-dipole coupling interaction when the $\mathrm{CO}$ coverage decreased $56,60,61$

After $\mathrm{CO}$ adsorption/desorption at $30^{\circ} \mathrm{C}$, we increased the temperature to $70^{\circ} \mathrm{C}$ under helium flow followed by $\mathrm{CO}$ adsorption. After flowing $\mathrm{CO}$ for $1 \mathrm{~min}$ (Fig. 2e, AD2-1min), a broad feature in the region $1925-1805 \mathrm{~cm}^{-1}$ is observed, which is consistent with $\mathrm{CO}$ adsorbed on the bridge and threefold hollow sites, indicating the formation of Pd clusters ${ }^{57,62}$. The feature at $2076 \mathrm{~cm}^{-1}$ increases in intensity during the $\mathrm{CO}$ adsorption process (AD2-1min to AD2-30 min). This is because of the Pd atoms moving back into the Au NPs during the helium purge as there is no driving force to stabilize Pd in the surface unless CO is present and this gradual increase of the atop CO peak is consistent with the high barriers for the diffusion of $\mathrm{Pd}$ atoms in the bulk of $\mathrm{Au}$ nanoparticles to the surface layer. In contrast, the Pd clusters are formed from the coalescence of surface Pd atoms, and since metal carbonyl species on the surface typically encounter lower diffusion barriers, their aggregation toward these clusters is a fast process ${ }^{63-65}$. The system was then rapidly cooled down to $30^{\circ} \mathrm{C}$ under helium flow to lock in the new structure of the catalyst. During the CO desorption process via helium purge (Fig. 2f), the broad peak at $1925-1805 \mathrm{~cm}^{-1}$ remains because CO binds more strongly to Pd clusters (Fig. 2e). Applying known extinction coefficients ${ }^{66}$ to our spectra in Fig. $2 \mathrm{f}$ -DE2-14min, which have a raw IR area ratio of linearly adsorbed CO to CO bound to more than one Pd of 1:25 leads to a corrected fraction of CO on isolated Pd sites to Pd clusters of $\sim 1: 1$ in the Pd cluster sample.

We then repeated the $\mathrm{CO}$ adsorption/desorption process at $30^{\circ} \mathrm{C}$. During the initial 21-min CO adsorption process at $30^{\circ} \mathrm{C}$, the peaks at $2173 \mathrm{~cm}^{-1}, \quad 2109 \mathrm{~cm}^{-1}, \quad 2076 \mathrm{~cm}^{-1}$, and $1925-1805 \mathrm{~cm}^{-1}$ (Fig. 2h) remain the same as those of CO adsorption at $70^{\circ} \mathrm{C}$, corresponding to the presence of Pd clusters in the Au NP surface. The broad IR peak at $1925-1805 \mathrm{~cm}^{-1}$ disappeared after $30 \mathrm{~min} \mathrm{CO}$ adsorption (Fig. 2h), AD3-30 min, and only the bands at $2114 \mathrm{~cm}^{-1}$ and $2064 \mathrm{~cm}^{-1}$ associated with atop-bound $\mathrm{CO}$ on $\mathrm{Au}$ and isolated $\mathrm{Pd}$ atoms remained after the desorption process (Fig. 2i). This indicates that the $\mathrm{CO}$ treatment at $30^{\circ} \mathrm{C}$ re-disperses Pd clusters back to Pd atoms (Fig. 2j). The complete absence of small clusters suggests that these species are unstable when the surface coverage of $\mathrm{CO}$ is high enough at $30^{\circ} \mathrm{C}$. Therefore, our in situ CO-DRIFTS experiments demonstrate the dynamic structural changes of our PdAu catalysts in response to $\mathrm{CO}$, from $\mathrm{Pd}$ single atoms to $\mathrm{Pd}$ clusters and redispersion back to single atoms, as a function of $\mathrm{CO}$ surface coverage which we control via temperature. While we find that the CO-induced rearrangement of Pd from atoms to clusters and then back to atoms is initially a reversible process, repeated cycling between phases leads to carbon buildup and eventual loss of complete reversibility of the process (see Supplementary Discussion and Supplementary Figs. S4 and S5).

Computational predictions of $\mathrm{CO}$-induced ensemble tuning effects in PdAu. To further probe the mechanistic origin of the experimental CO-DRIFTS results, we performed on-lattice firstprinciples based MC simulations. These simulations account for important components of the free energy such as the configurational entropy contribution and the loss of translational and rotational degrees of freedom of $\mathrm{CO}$ upon adsorption.

In the presence of $\mathrm{CO}$ and at temperatures higher than $27^{\circ} \mathrm{C}$, the low-index (111) facet is expected to be the predominant one on $\mathrm{Au} \mathrm{NPs}{ }^{67}$. Therefore, our MC simulations focus on this latter surface and capture the restructuring of the top layer of the $\mathrm{PdAu}$ alloy when exposed to $\mathrm{CO}^{43}$. Indeed, the CO-DRIFTS results indicate that equilibrium with respect to the catalyst structure is reached within the presented experimental timescales (Fig. 2). For example, we note that the peak which is associated with $\mathrm{CO}$ adsorbed atop on $\mathrm{Pd}\left(2076 \mathrm{~cm}^{-1}\right)$ exhibits very similar intensities in Fig. $2 b, e, h$ after the longest time interval of $\mathrm{CO}$ exposure. On this basis, the goal of the MC simulation is to elucidate the most thermodynamically stable Pd configurations, while modeling of the dynamic restructuring of the PdAu catalyst that includes kinetic barriers for surface (restructuring) processes (e.g., atomic swaps, Pd segregation from the bulk to the surface layer) is part of ongoing work. Moreover, our DFT calculations indicate that the binding strength of $\mathrm{CO}$ on the $\mathrm{Au}(111)$ surface is only weakly perturbed by the presence of subsurface Pd clusters $(\sim 60 \mathrm{meV}$ stronger $\mathrm{CO}$ binding on an $\mathrm{Au}(111)$ surface with a four atom $\mathrm{Pd}$ cluster in the subsurface layer than on a pure $\mathrm{Au}(111)$ slab-see Supplementary Fig. S9).

The interaction of $\mathrm{CO}$ with metal surfaces is known to be challenging to reproduce quantitatively with $\mathrm{DFT}^{68-70}$, and therefore we performed a sensitivity analysis to understand the effect of the binding strength of $\mathrm{CO}$ on the population of different Pd structures (i.e., Pd monomers, Pd-Pd dimers, and Pd trimers) (Supplementary Fig. S8). We find that DFT appears to overestimate the CO-binding energy as evidenced by (i) the absence of $\mathrm{Pd}$ clusters for the experimental conditions of $70^{\circ} \mathrm{C}$ and $\mathrm{P}_{\mathrm{CO}}=0.1$ bar, and (ii) the systematically lower vibrational frequencies for $\mathrm{CO}$ chemisorption on $\mathrm{Pd}$ atoms and aggregates in the $\mathrm{Pd} / \mathrm{Au}(111)$ surface. In particular, the computed vibrational frequencies of $\mathrm{CO}$ on $\mathrm{Pd}$ atop, $\mathrm{Pd}-\mathrm{Pd}$ bridge, and threefold sites are $2018 \mathrm{~cm}^{-1}, 1859 \mathrm{~cm}^{-1}$, and $1755 \mathrm{~cm}^{-1}$, respectively, which are lower than the corresponding experimental values (i.e., $2076 \mathrm{~cm}^{-1}$, for Pd atop and between 1925 and $1805 \mathrm{~cm}^{-1}$ for Pd bridge and threefold), thereby indicating that the binding strength of CO is, in every case, overestimated by $\mathrm{DFT}^{56,62}$. In view of this, in our model we use a CO-binding energy which is lower than the DFT computed one by $0.2 \mathrm{eV}$; equivalently adsorption energy shifted by $+0.2 \mathrm{eV}$, which is within the widely accepted error of $\mathrm{DFT}^{71}$. This value reproduces substantial populations of $\mathrm{Pd}$ clusters, in line with experimental data for the aforementioned conditions.

We began the simulations by computing the fractions $\left(\overline{Y_{k}}\right)$ of the different surface species (i.e., Pd monomers and Pd clusters) for $\mathrm{P}_{\mathrm{CO}}=0.1$ bar and within the temperature range of $30-70^{\circ} \mathrm{C}$. Under these conditions, a $40^{\circ} \mathrm{C}$ increase in temperature brings about a reduction of $\mathrm{CO}$ dopant fractional coverage $\left(\Omega_{\mathrm{CO}}\right)$ from ca. 0.99 to 0.75 (Fig. 3a). In turn, the decreased $\Omega_{\mathrm{CO}}$ induces the surface aggregation of Pd atoms (Fig. 3a), thus elucidating the observed trends in the DRIFT spectra (Fig. 2). We also find that the majority of Pd clusters (ca. 77\%) consist of Pd-Pd dimers (Supplementary Table S2 and Fig. 3b). The rest of the surface 
(a)

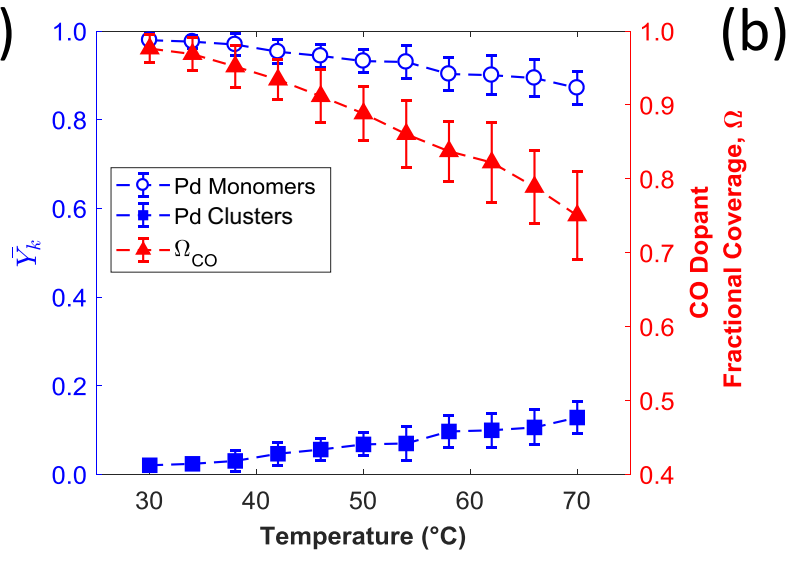

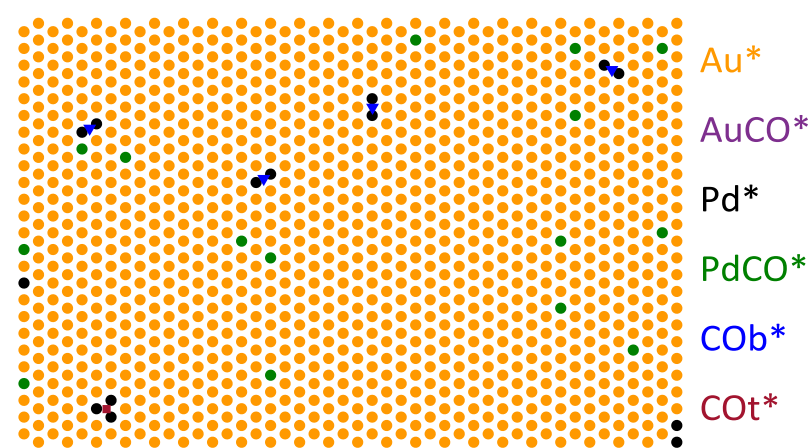

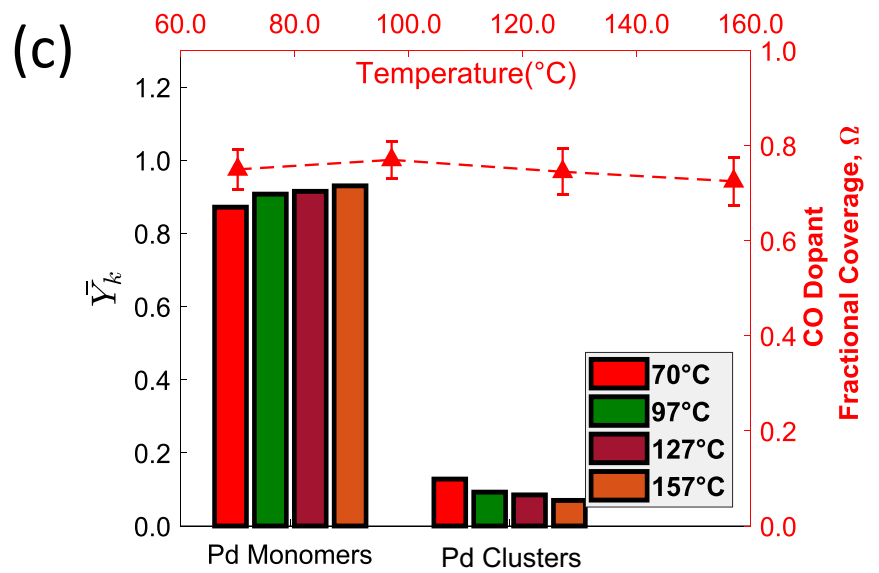

Fig. 3 Computational investigations of CO-induced Pd clusters formation in Pd/Au. a Fractions of the different surface species $\left(\overline{Y_{k}}\right)$ and $C O$ dopant fractional coverage $\left(\Omega_{\mathrm{CO}}\right)$ at temperatures within the $30-70{ }^{\circ} \mathrm{C}$ range for $E_{\text {ads }}(\mathrm{CO})$ on $\mathrm{Pd}$ surface species that are shifted by $+0.2 \mathrm{eV}$ as compared to the DFT-predicted values; $\mathrm{P}_{\mathrm{CO}}=0.1$ bar for all calculations. b Representative $\mathrm{MC}$ snapshot at $70^{\circ} \mathrm{C}$ that shows that the majority of $\mathrm{Pd}$ aggregates are $\mathrm{Pd}-\mathrm{Pd}$ dimers. $\mathrm{Pd}, \mathrm{Au}$, and $\mathrm{Pd}$ atoms with adsorbed $\mathrm{CO}$ are shown in black, yellow, and green, respectively. Bridge sites between $\mathrm{Pd}$ atoms, Au atoms covered by $\mathrm{CO}$, and empty hollow sites are shown in light green, blue, and gray, respectively. Panel (b) shows only part of the MC lattice. (c) $\overline{Y_{k}}$ and $\Omega_{\mathrm{CO}}$ at four different temperatures for $\Omega_{\mathrm{CO}} \sim 0.75$. The error bars in panels (a) and (c) are \pm 1 standard deviation.

species contain mainly $\mathrm{Pd}$ trimers, while the fraction of $\mathrm{Pd}$ clusters with more than $3 \mathrm{Pd}$ atoms is extremely small under the investigated conditions and such clusters rarely appear on the MC lattice (Supplementary Table S2).

Besides $\Omega_{\mathrm{CO}}$, there is also an important effect of temperature on the distribution of Pd surface species. To clarify this effect, we have carried out representative $\mathrm{MC}$ simulations for three additional temperatures $\left(T=97^{\circ} \mathrm{C}, 127^{\circ} \mathrm{C}\right.$, and $\left.157^{\circ} \mathrm{C}\right)$, while applying a $\mathrm{P}_{\mathrm{CO}}$ that maintains $\Omega_{\mathrm{CO}} \sim 0.75$ (i.e., the computed $\Omega_{\mathrm{CO}}$ value at $\mathrm{P}_{\mathrm{CO}}=0.1$ bar and $70{ }^{\circ} \mathrm{C}$ in Fig. $\left.3 \mathrm{a}-\mathrm{c}\right)$. Our $\mathrm{MC}$ simulations indicate that the average fraction of $\mathrm{Pd}$ clusters diminishes at a higher temperature and that the SAA phase gains in thermodynamic stability (Fig. 3c). Thus, we postulate that at very high $T$ (higher than $300^{\circ} \mathrm{C}$ as shown in Supplementary Fig. S3), Pd aggregates will tend to disperse to single atoms. Indeed, one may expect that higher temperatures, which increase the entropy of the system, would favor the SAA phase owing to its higher disorder as compared to Pd clusters.

Ethanol dehydrogenation on $\mathrm{Pd}_{0.02} \mathrm{Au}_{0.98} / \mathrm{SiO}_{2}$ after $\mathrm{CO}$ treatment. To understand the effect of the different Pd ensembles of the $\mathrm{Pd}_{0.02} \mathrm{Au}_{0.98} / \mathrm{SiO}_{2}$ samples on catalytic performance, ethanol dehydrogenation (EDH) was chosen as a probe reaction. $\mathrm{SiO}_{2}$ was used as an inert support and did not show any activity in the
$\mathrm{EDH}$ reaction below $400{ }^{\circ} \mathrm{C}^{20}$. It has been reported that $\mathrm{NiCu} /$ $\mathrm{SiO}_{2}$ and $\mathrm{NiAu} / \mathrm{SiO}_{2}$ SAAs catalyze the $\mathrm{EDH}$ reaction with $100 \%$ selectivity to acetaldehyde and $\mathrm{H}_{2}$, whereas catalysts consisting of Ni clusters break the $\mathrm{C}-\mathrm{C}$ bond of ethanol, leading to enhanced activity but decreased selectivity, yielding $\mathrm{CO}$ and $\mathrm{CH}_{4}{ }^{21,72}$. $\mathrm{PdCu} / \mathrm{SiO}_{2} \mathrm{SAA}^{20}$ and atomically dispersed $\mathrm{Pd} / \mathrm{ZnO}^{73}$ catalysts have also exhibited $100 \%$ selectivity to acetaldehyde and $\mathrm{H}_{2}$ in $\mathrm{EDH}$, while Pd clusters lead to the decomposition of ethanol to CO. Evans et al. ${ }^{74}$ and Li et al. ${ }^{75}$ conducted computational studies of the $\mathrm{EDH}$ reaction mechanism on $\mathrm{Pd} / \mathrm{Au}(111)$ surface alloys, demonstrating that $\mathrm{Pd}$ is the active site and the activity and selectivity of the reaction is heavily dependent on the type of $\mathrm{Pd}$ ensembles. These prior data suggest that $\mathrm{PdAu} / \mathrm{SiO}_{2}$ catalysts in the SAA or cluster phases should exhibit different catalytic performance for the $\mathrm{EDH}$ reaction.

We tested our $\mathrm{Pd}_{0.02} \mathrm{Au}_{0.98} / \mathrm{SiO}_{2}$ catalysts for the $\mathrm{EDH}$ reaction after different $\mathrm{CO}$ pretreatment conditions. As depicted in Fig. 4b, after $\mathrm{H}_{2}$ reduction at $200{ }^{\circ} \mathrm{C}$, the reduced $\mathrm{Pd}_{0.02} \mathrm{Au}_{0.98} / \mathrm{SiO}_{2} \mathrm{SAA}$ (Fig. 4a) exhibited low ethanol conversion $(<20 \%)$ and $100 \%$ selectivity to acetaldehyde and $\mathrm{H}_{2}$ up to $300^{\circ} \mathrm{C}$. At temperatures above $350^{\circ} \mathrm{C}, \mathrm{CO}$ and methane is formed, which is characteristic of higher temperature Au chemistry (Supplementary Fig. S6) 76,77. We then cooled the sample to $150^{\circ} \mathrm{C}$ in ethanol flow, and a second reaction test was carried out while ramping the temperature from $150{ }^{\circ} \mathrm{C}$ to $400^{\circ} \mathrm{C}$. As can be seen in Fig. 4 b, 
(a)

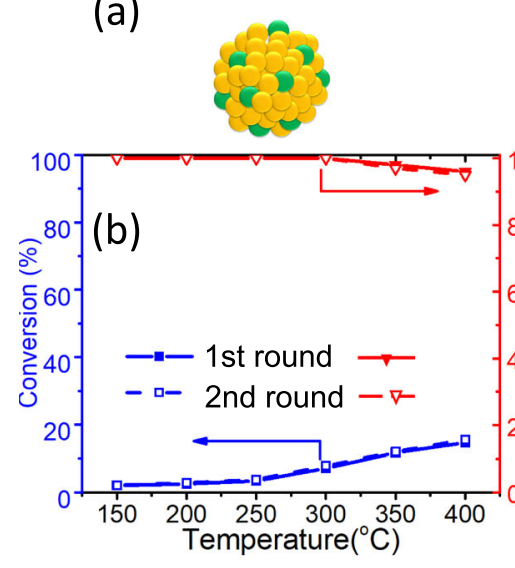

(c)

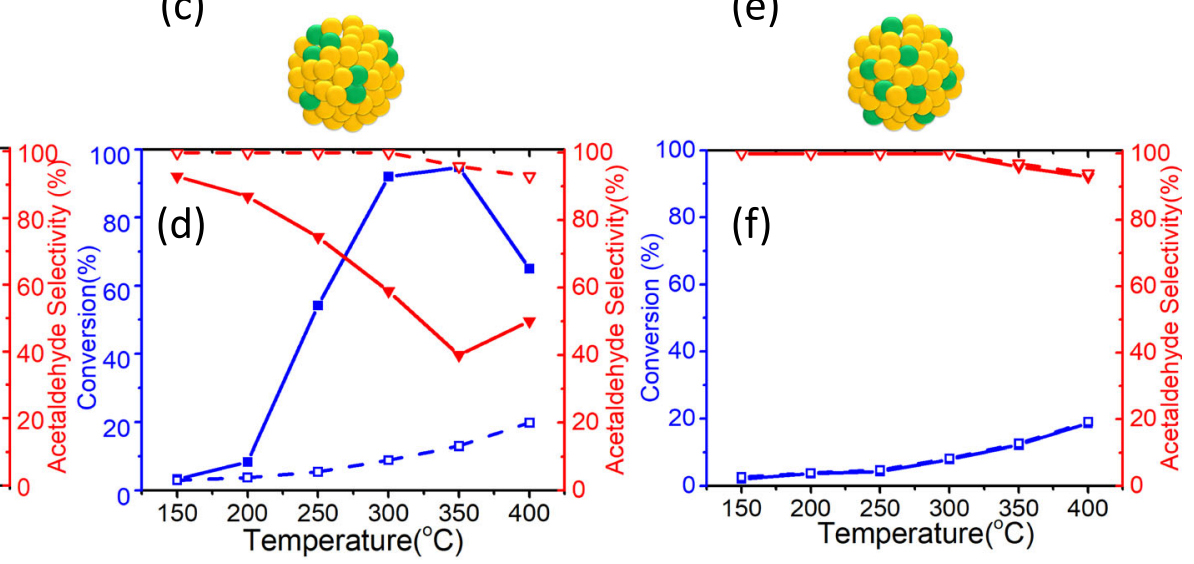

(e)

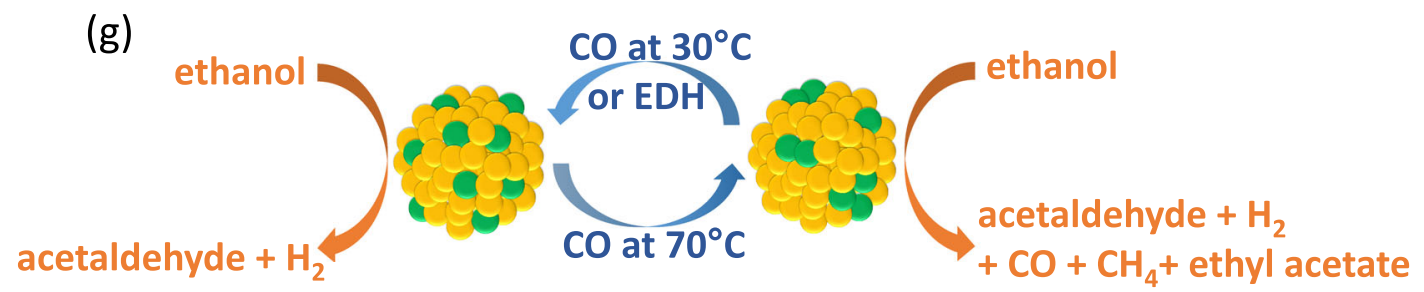

Fig. 4 In situ control over a reaction pathway via $\mathbf{C O}$ treatment. Structure $(\mathbf{a}, \mathbf{c}, \mathbf{e})$ and catalytic performance $(\mathbf{b}, \mathbf{d}, \mathbf{f})$ of a $\mathrm{Pd} \mathrm{O}_{02} \mathrm{Au} \mathrm{O}_{0.98} / \mathrm{SiO}_{2}$ sample after (a, b) no CO treatment, (c, d) $\mathrm{CO}$ at $30^{\circ} \mathrm{C}$ for 30 min then $70{ }^{\circ} \mathrm{C}$ for 30 min which causes $\mathrm{Pd}$ to form clusters, (e, f) $\mathrm{CO}$ treatment at $30{ }^{\circ} \mathrm{C}$ for 30 min, then $70^{\circ} \mathrm{C}$ for $30 \mathrm{~min}$, then $30^{\circ} \mathrm{C}$ for $1 \mathrm{~h}$ which causes $\mathrm{Pd}$ to aggregate and then re-disperse back into atoms. $\mathbf{g}$ Schematic illustration showing how CO treatment can be used to change Pd from atoms to clusters and back, and the effect of these different active sites on reaction pathway. Ethanol dehydrogenation $(\mathrm{EDH})$ reaction conditions: $300 \mathrm{mg}$ catalyst, $2 \%$ ethanol in helium, total flow rate $12 \mathrm{~mL} / \mathrm{min}, \mathrm{GHSV}=2400 \mathrm{~mL} /\left(\mathrm{h} \bullet \mathrm{g}_{\text {cat }}\right) . \mathrm{Each}$ temperature was held for $2 \mathrm{~h}$. The solid line shows the first-round $\mathrm{EDH}$ reaction from $150^{\circ} \mathrm{C}$ to $400^{\circ} \mathrm{C}$; the dotted line is the second round reaction. Each point is the average of data obtained during $2 \mathrm{~h}$.

the catalytic performance during the second round was the same as that of the first round, which indicates that the SAA catalyst is stable under $\mathrm{EDH}$ reaction conditions. Compared to the performance of the $\mathrm{Au} / \mathrm{SiO}_{2}$ catalyst (Supplementary Fig. S6), the addition of isolated $\mathrm{Pd}$ atoms to Au leads to an increase in the ethanol conversion while maintaining the high selectivity, illustrating the beneficial role of single Pd atoms, which is in line with literature reports ${ }^{74,75}$.

In Fig. $4 d$, we treated the reduced $\mathrm{Pd}_{0.02} \mathrm{Au}_{0.98} / \mathrm{SiO}_{2} \mathrm{SAA}$ first under $\mathrm{CO}$ at $30^{\circ} \mathrm{C}$ and then $70^{\circ} \mathrm{C}$ (following the protocol used in the IR experiments) in order to drive the system towards the $\mathrm{Pd}$ cluster phase (Fig. 4c), as confirmed by the CO-DRIFTS results in Fig. 2f. The presence of Pd clusters in the catalyst leads to a dramatic increase in ethanol conversion at each temperature (up to $90 \%$ at $300{ }^{\circ} \mathrm{C}$ ) compared to the SAA phase in Fig. 4 b. Ethyl acetate was formed starting at $150{ }^{\circ} \mathrm{C}$ and decomposition products $\mathrm{CO}$ and $\mathrm{CH}_{4}$ were formed starting at $200{ }^{\circ} \mathrm{C}$, leading to a significant decrease in acetaldehyde selectivity. The increased ethanol conversion and decreased selectivity observed in our study are in line with the reported behavior of Pd clusters in $\mathrm{Pd} /$ $\mathrm{Au}(111), \mathrm{PdCu}$, and $\mathrm{Pd} / \mathrm{ZnO}$ catalysts for the $\mathrm{EDH}$ reaction ${ }^{20,73-75}$. We do not expect that $\mathrm{CO}$ formed during the reaction has any effect on the aggregation of $\mathrm{Pd}$ atoms because the maximum amount of $\mathrm{CO}$ formed in the product stream at the high-temperature extreme $\left(350{ }^{\circ} \mathrm{C}\right)$ is only $0.6 \%$, which is small compared to the $10 \% \mathrm{CO}$ we used to control the Pd sites.

In the second round of tests, we cooled the sample to $150^{\circ} \mathrm{C}$ under ethanol flow and ran the reaction tests up to $400^{\circ} \mathrm{C}$ (Fig. 4d). We found under these conditions the original Pd cluster catalyst behaved like the pristine SAA catalyst, with low ethanol conversion $(<20 \%)$ and $100 \%$ selectivity to acetaldehyde and hydrogen up to $300^{\circ} \mathrm{C}$. These results indicate that $\mathrm{Pd}$ clusters re-disperse back to $\mathrm{Pd}$ atoms under $\mathrm{EDH}$ reaction conditions. Therefore, we further checked the stability of the cluster Pd phase of the catalyst by carrying out longer performance tests. The performance of the $\mathrm{Pd}$ cluster catalyst was stable at $250{ }^{\circ} \mathrm{C}$ (Supplementary Fig. S3a). We noticed a significant decrease in ethanol conversion and increased acetaldehyde selectivity of the catalyst from $300{ }^{\circ} \mathrm{C}$ to $400{ }^{\circ} \mathrm{C}$ during a $60 \mathrm{~h}$ run and finally the same ethanol conversion and acetaldehyde selectivity as the pristine $\mathrm{PdAu} / \mathrm{SiO}_{2} \mathrm{SAA}$ catalyst is reached at $400{ }^{\circ} \mathrm{C}$ (Supplementary Fig. S3b). This result indicates that $\mathrm{Pd}$ clusters are not stable and revert to isolated $\mathrm{Pd}$ atoms at $400{ }^{\circ} \mathrm{C}$ under $\mathrm{EDH}$ reaction conditions. This conclusion is further supported by our MC simulations showing that elevated temperatures favor single $\mathrm{Pd}$ atoms as shown in Fig. $3 \mathrm{c}^{43}$.

In Fig. $4 \mathrm{f}$, the reduced $\mathrm{Pd}_{0.02} \mathrm{Au}_{0.98} / \mathrm{SiO}_{2} \mathrm{SAA}$ was treated with $\mathrm{CO}$ at $30^{\circ} \mathrm{C}, 70{ }^{\circ} \mathrm{C}$ then $30^{\circ} \mathrm{C}, 100 \%$ acetaldehyde selectivity was retrieved, and it behaved similarly to the pristine $\mathrm{Pd}_{0.02} \mathrm{Au}_{0.98} /$ $\mathrm{SiO}_{2}$ SAA catalyst over two cycles. This result indicates that $\mathrm{Pd}$ aggregates formed at $70^{\circ} \mathrm{C}$ re-disperse back to atoms after subsequent $30^{\circ} \mathrm{C} \mathrm{CO}$ treatment (Fig. 4e). The catalytic performance of a control $\mathrm{Au} / \mathrm{SiO}_{2}$ catalyst sample did not show any changes after these different $\mathrm{CO}$ treatments. In addition, in situ ethanol-DRIFTS reveal the increased reactivity of Pd clusters present in the catalyst after the $70{ }^{\circ} \mathrm{C} \mathrm{CO}$ treatment by the small number of ethoxy species left after the helium purge (Supplementary Fig. S1). This contrasts with the abundant ethoxy species left on the less reactive but more selective SAA catalyst (Supplementary Fig. S1), which is consistent with the reactor data.

These reaction results, coupled with the CO-DRIFTS and ethanol-DRIFTS data, demonstrate how CO-induced dynamic structural changes from a SAA to a Pd cluster structure can be 
induced and can be used to control reactivity and selectivity in the $\mathrm{EDH}$ reaction (Fig. 4g). We further demonstrate that the $\mathrm{Pd}$ clusters themselves slowly disperse back to $\mathrm{Pd}$ atoms at high temperature during the $\mathrm{EDH}$ reaction, hence the $\mathrm{EDH}$ reaction itself serves to stabilize the SAA structure which is most favorable for high reaction selectivity.

In summary, guided by DFT calculations we have demonstrated experimentally that the surface coverage of CO can be used to transition a PdAu alloy catalyst in situ between a SAA and a Pd cluster structure. Specifically, at a set CO pressure and lower temperature, the SAA is favored vs. at higher temperature, at which the lower $\mathrm{CO}$ surface coverage leads to the formation of $\mathrm{Pd}$ clusters. We further demonstrate that these two catalyst structures have distinctly different reactivity for the $\mathrm{EDH}$ reaction; the SAA phase is active for $\mathrm{C}-\mathrm{H}$ activation but not C-C scission, yielding $100 \%$ selectivity to acetaldehyde and hydrogen, while Pd clusters decompose the ethanol leading to the formation of $\mathrm{CO}$ among other products. Furthermore, over time, and in the absence of $\mathrm{CO}$, the $\mathrm{EDH}$ reaction itself re-disperses $\mathrm{Pd}$ clusters back to atoms with a concurrent change in the EDH reaction pathway. This in situ control of the atomic-scale surface structure in a bimetallic catalyst via $\mathrm{CO}$ treatment enables control over a reaction pathway. Our DFT calculations on a wide variety of other systems indicate that this approach is not unique to $\mathrm{PdAu}$ and should be generalizable to other bimetallic catalytic systems like $\mathrm{NiAu}$ and $\mathrm{RhAu}{ }^{42-44}$.

\section{Methods}

Material synthesis. $\mathrm{PdAu} / \mathrm{SiO}_{2}$ SAAs were prepared using sequential reduction, as previously reported ${ }^{53}$. Briefly, Au NPs were synthesized using $0.3 \mathrm{~g} \mathrm{HAuCl}_{4} \cdot 3 \mathrm{H}_{2} \mathrm{O}$, $1.2 \mathrm{~g}$ poly(vinylpyrrolidone) (PVP, $\mathrm{MW}=58,000$ ), and $0.3 \mathrm{~g} \mathrm{NaHCO}_{3}$ in $50 \mathrm{~mL}$ of ethylene glycol. The solution was heated to $90^{\circ} \mathrm{C}$ and held for half an hour under nitrogen flow. The solution was then cooled to ambient temperature and the desired amount of $\mathrm{Pd}\left(\mathrm{NO}_{3}\right)_{2} \cdot \mathrm{xH}_{2} \mathrm{O}$ was added. This solution was heated to $90{ }^{\circ} \mathrm{C}$ with vigorous stirring and held for $8 \mathrm{~h}$. The resulting PdAu NPs were mixed with fumed silica (heat-treated in air at $650^{\circ} \mathrm{C}$ for $3 \mathrm{~h}$ ), dispersed in ethanol, and stirred overnight. The slurry carrying the supported NPs was washed and dried in a vacuum for $24 \mathrm{~h}$ before being calcined in air at $350{ }^{\circ} \mathrm{C}$ for $4 \mathrm{~h}$ resulting in $\mathrm{Pd}_{0.02} \mathrm{Au}_{0.98} / \mathrm{SiO}_{2}$ catalysts. $\mathrm{Au} / \mathrm{SiO}_{2}$ catalysts were synthesized using the same procedure without the addition of $\mathrm{Pd}\left(\mathrm{NO}_{3}\right)_{2} \cdot \mathrm{xH}_{2} \mathrm{O}$.

Characterization. $\mathrm{PdAu} / \mathrm{SiO}_{2}$ samples were dissolved in concentrated $\mathrm{HCl}$ and $\mathrm{H}_{2} \mathrm{O}_{2}$ to prepare them for inductively coupled plasma atomic emission spectroscopy (ICP-AES) with a Leeman Labs PS1000 instrument.

Diffuse reflectance infrared Fourier transform spectroscopy (DRIFTS) was performed on a Thermo Scientific Nicolet iS50 FTIR spectrometer using a Praying Mantis high-temperature reaction chamber with a gas inlet and vent to allow the flow of pretreatment and reactant gases. Liquid nitrogen cooled MCT detector was used, and spectra acquired from 120 scans at $4 \mathrm{~cm}^{-1}$ resolution.

For in situ CO-DRIFTS, prior to spectra collection $10 \mathrm{mg} \mathrm{PdAu} / \mathrm{SiO}_{2}$ samples were reduced in $10 \% \mathrm{H}_{2} / \mathrm{He}$ at $200{ }^{\circ} \mathrm{C}$ for $1 \mathrm{~h}$, then purged with $\mathrm{He}$ and cooled down to $70{ }^{\circ} \mathrm{C}$ and $30^{\circ} \mathrm{C}$ to acquire background spectra (Supplementary Fig. S2). $10 \% \mathrm{CO} / \mathrm{He}$ was introduced into the cell to allow the adsorption of CO (noted as $\mathrm{AD}$ ), then the system was quickly cooled down to $30^{\circ} \mathrm{C}$ to freeze the structure of the sample and flushed with helium to remove any gas-phase CO (noted as DE), which has vibrational bands that overlap with peaks associated with surfaceadsorbed CO. During the process, time-dependent spectra were recorded. The baseline was collected under He before any $\mathrm{CO}$ was introduced.

For in situ ethanol-DRIFTS, $10 \mathrm{mg}$ of samples were pretreated in situ at $200{ }^{\circ} \mathrm{C}$ with a $10 \% \mathrm{H}_{2} / \mathrm{He}$ mixture for $1 \mathrm{~h}$ prior to purging with helium. The background spectra were collected under helium at $200^{\circ} \mathrm{C}$ and $130{ }^{\circ} \mathrm{C}$ (Supplementary Fig. S2), respectively. Then some catalysts underwent $\mathrm{CO}$ treatment and others that did not served as controls. Catalysts were then saturated with vaporized ethanol carried by a helium flow at $130{ }^{\circ} \mathrm{C}$ or $200^{\circ} \mathrm{C}$ (noted as AD). When the IR spectra did not change with time, meaning the saturation was complete, a helium purge was conducted to remove gaseous ethanol and characterize the sample surface (noted as DE).

Temperature-programmed oxidation (TPO) was carried out in a Micromeritics AutoChem II 2920 instrument equipped with a Blazer ThermoStar quadrupole mass spectrometer. Fragments of $m / z=32,44$, and 18, corresponding to $\mathrm{O}_{2}, \mathrm{CO}_{2}$, and $\mathrm{H}_{2} \mathrm{O}$ were monitored using the mass spectrometer. The test was performed on the $100 \mathrm{mg}$ as-synthesized $\mathrm{Pd}_{0.02} \mathrm{Au}_{0.98} / \mathrm{SiO}_{2}, \mathrm{Au} / \mathrm{SiO}_{2}$ catalysts, and $\mathrm{SiO}_{2}$ support, which was first calcined in $3 \% \mathrm{O}_{2} / \mathrm{Ar}$ at $350{ }^{\circ} \mathrm{C}$ for $1 \mathrm{~h}$, then reduced under $10 \% \mathrm{H}_{2} /$
Ar at $200^{\circ} \mathrm{C}$ for $1 \mathrm{~h}$. The temperature was then lowered to $35^{\circ} \mathrm{C}$, and some samples were exposed to the $10 \% \mathrm{CO} / \mathrm{He}$ treatment at $35^{\circ} \mathrm{C}$ and/or $70{ }^{\circ} \mathrm{C}$, while some were not as indicated in Supplementary Fig. S4b. Then a He purge at $300^{\circ} \mathrm{C}$ for $1 \mathrm{~h}$ was conducted to remove both surface-adsorbed $\mathrm{CO}$ and gaseous $\mathrm{CO}$. Finally, the sample underwent TPO with $3 \% \mathrm{O}_{2} / \mathrm{Ar}$ from $40{ }^{\circ} \mathrm{C}$ to $600{ }^{\circ} \mathrm{C}$ at a rate of $2{ }^{\circ} \mathrm{C} / \mathrm{min}$. The products $\left(\mathrm{H}_{2} \mathrm{O}\right.$ and $\left.\mathrm{CO}_{2}\right)$ were monitored using a quadrupole mass spectrometer.

Catalytic activity measurements. The ethanol dehydrogenation activity of the $\mathrm{PdAu} / \mathrm{SiO}_{2}$ samples was evaluated in a fixed-bed flow reactor at atmospheric pressure. Typically, a $300 \mathrm{mg}$ of sample mixed with $700 \mathrm{mg}$ of silica sand was loaded into a quartz reactor tube packed in between two quartz wool plugs. The reactor was heated in a furnace equipped with a temperature controller. The temperature of the catalyst was measured with a K-type thermocouple in contact with the top of the catalyst bed. Before reaction, the catalyst was reduced with $10 \%$ $\mathrm{H}_{2} / \mathrm{He}$ at $200{ }^{\circ} \mathrm{C}$ for $2 \mathrm{~h}$. Ethanol was injected into a flow of pure He by a syringe pump and vaporized in the heated gas line before entering the reactor. The ethanol concentration was $2 \mathrm{wt} . \%$ and the total flow rate was $12 \mathrm{~mL} / \mathrm{min}$, corresponding to a gas hourly space velocity (GHSV) of $2400 \mathrm{~mL} /\left(\mathrm{h} \cdot \mathrm{g}_{\text {cat }}\right)$. The effluent products were monitored online by two gas chromatographers in series. The first gas chromatograph (HP 5890) with an HPLQ capillary column (Hewlett-Packard Company, $30 \mathrm{~m} \times 0.32 \mathrm{~mm} \times 0.50 \mu \mathrm{m}$ ) was equipped with a thermal conductivity detector (TCD) to monitor ethanol, acetaldehyde, ethyl acetate, or other oxygenates. Then the gas went through the condenser and the effluent was monitored via a SRI 331 gas chromatograph equipped with a Carbosphere 80/100 packed column and TCD detector to monitor $\mathrm{CO}, \mathrm{CH}_{4}$, and $\mathrm{CO}_{2}$.

Density functional theory calculations. DFT calculations were carried out using the Vienna Ab initio Simulation Package (VASP) ${ }^{78,79}$. All calculations were performed within the generalized gradient approximation (GGA), and the revised Perdew-Burke-Ernzerhof (RPBE) functional was employed to treat exchange and correlation effects ${ }^{80,81}$. The interactions between the frozen core and valence electrons were described by the projector augmented wave (PAW) $\operatorname{method}^{82}$, and the kinetic energy cutoff for the plane-wave basis set was $400 \mathrm{eV}$. The chemisorption of $\mathrm{CO}$ on PdAu alloy surfaces was explored using a five-layer $p(3 \times 3)$ slab, and the Brillouin zone was sampled with a $13 \times 13 \times 1$ Monkhorst-Pack k-point mesh. During geometry optimization, the two bottom Au layers were kept fixed at the RPBE-calculated Au lattice constant (i.e., $4.22 \AA)^{83}$, while the three top layers and any adsorbate species were allowed to fully relax. Electronic self-consistency was achieved up to a tolerance of $10^{-7} \mathrm{eV} / \AA$, and the force convergence criterion for the ions that were free to move was $0.01 \mathrm{eV} / \AA ̊$. Vibrational analyses were performed under the harmonic approximation with a finite-difference displacement of $0.02 \AA$

The adsorption energy of $m$ CO molecules was computed using the following expression:

$$
E_{\text {ads }}(m \times \mathrm{CO})=E_{\text {tot }}^{m \times \mathrm{CO}+\text { slab }}-E_{\text {tot }}^{\text {slab }}-m \times E_{\text {tot }}^{\mathrm{CO}_{(g)}},
$$

where $E_{\text {tot }}^{m \times \mathrm{CO}+\text { slab }}$ is the DFT total energy of $\mathrm{m}$ chemisorbed CO molecules on the PdAu surface, $E_{\text {tot }}^{\text {slab }}$ is the DFT total energy of the clean slab, and $E_{\text {tot }}^{\mathrm{CO}_{(g)}}$ is the DFT total energy of a $\mathrm{CO}$ molecule in the gas phase. According to this definition, the more negative the $E_{\text {ads }}(m \times \mathrm{CO})$ value, the stronger the binding of $\mathrm{CO}$ on the PdAu surface.

The surface segregation energy $\left(\Delta E_{\text {seg }}\right)$ indicates the thermodynamic preference of Pd atoms to reside in the bulk of the Au matrix or in the surface layer. Similar to our previous works, the segregation energies in the absence $\left(\Delta E_{\mathrm{seg}}\right)$ and in the presence of $\mathrm{CO}\left(\Delta E_{\mathrm{seg}}^{\mathrm{CO}}\right)$ were defined by Eq. (2) and Eq. (3), respectively.

$$
\begin{gathered}
\Delta E_{\text {seg }}=E_{\text {tot }, \text { Bulk }}-E_{\text {tot, }, \mathrm{SAA}}, \\
\Delta E_{\text {seg }}^{\mathrm{CO}}=\Delta E_{\text {seg }}+\left\{E_{\text {ads }}^{\text {host }}(\mathrm{CO})-E_{\text {ads }}^{\mathrm{SAA}}(\mathrm{CO})\right\},
\end{gathered}
$$

where $E_{\text {tot.Bulk }}$ is the DFT total energy of a Pd atom placed in the third layer of the slab; $E_{\text {tot,SAA }}$ is the DFT total energy of the Au slab with a Pd atom in the surface layer; $E_{\text {ads }}^{\text {host }}(\mathrm{CO})$ is the adsorption energy of a CO molecule on the top site of an $\mathrm{Au}$ atom and $E_{\text {ads }}^{\mathrm{SAA}}(\mathrm{CO})$ is the adsorption energy of a CO molecule on the SAA surface. Negative values of the segregation energy suggest a preference of $\mathrm{Pd}$ to move from the surface into the bulk of $\mathrm{Au}$, while positive values imply the opposite.

Moreover, the thermodynamic stability of Pd aggregates on the surface layer of the PdAu alloy (e.g., Pd-Pd dimers) can be compared to the stability of single Pd atoms thereon by means of the aggregation energy $\left(\Delta E_{\mathrm{agg}}\right)$. The latter energy, under vacuum conditions, is given by Eq. (4) while in the presence of chemisorbed CO is given by Eq. (5).

$$
\begin{gathered}
\Delta E_{\text {agg }}=E_{\text {tot }}(n)+(n-1) \times E_{\text {tot }}(\text { host })-n \times E_{\text {tot }}(\mathrm{SAA}), \\
\Delta E_{\text {agg }}^{m \times \mathrm{CO}}(n)=\Delta E_{\text {agg }}(n)-\left\{m \times E_{\text {ads }}^{\mathrm{SAA}}(\mathrm{CO})-E_{\text {ads }}^{n-\mathrm{mer}}(m \times \mathrm{CO})\right\},
\end{gathered}
$$

where $E_{\text {tot }}(n), E_{\text {tot }}$ (host), and $E_{\text {tot }}(\mathrm{SAA})$ are the DFT total energies of an alloy with an aggregate of $n$ Pd atoms, the pure host material, and the SAA, respectively; 
$E_{\text {ads }}^{n-\text { mer }}(\mathrm{CO})$ and $E_{\text {ads }}^{\mathrm{SAA}}(\mathrm{CO})$ are the computed adsorption energies of the most stable configuration of $m \mathrm{CO}$ molecules on a Pd aggregate with $n$ atoms, and of a $\mathrm{CO}$ molecule on the top dopant site of the Pd monomer, respectively. Finally, based on the definition of $\Delta E_{\text {agg }}$ in Eq. (4) and Eq. (5), negative values of $\Delta E_{\text {agg }}$ suggest that the formation of aggregates of Pd atoms is thermodynamically favored over the formation of isolated Pd atoms, while the opposite is true for $\Delta E_{\mathrm{agg}}>0$.

Monte Carlo simulations. On-lattice MC simulations were performed using Zacros (version 2.0) ${ }^{84-86}$, a software application that employs the graph-theoretical framework of Stamatakis et al. ${ }^{87-91}$. This framework is equally effective in performing equilibrium (Markov Chain MC (MCMC)) or dynamic (kinetic MC (KMC) ) simulations of physicochemical phenomena on surfaces. For a surface represented by a lattice, the accessible (micro)states within the state space $\boldsymbol{\Omega}$ capture all possible arrangements of adsorbates thereon, and the MC method simulates state-to-state transitions within $\boldsymbol{\Omega}$. Supplementary Figs. S11 and S12 summarize the possible transitions in our simulations, which include adsorption, desorption and diffusion of $\mathrm{CO}$, and $\mathrm{Pt}-\mathrm{Au}$ atomic swaps. The probability of finding the system in state $i, \mathrm{P}_{i}(\mathbf{t})$, is given by the Markovian Master Equation:

$$
\frac{\mathrm{d} P_{i}(t)}{\mathrm{d} t}=-\sum_{i \neq j} k_{i j} P_{i}(t)+\sum_{i \neq j} k_{j i} P_{j}(t)
$$

where $k_{i j}$ and $k_{j i}$ are the rate constants of surface processes that bring the system from state $i$ to state $j$ and vice versa. Realizations (sample trajectories) of the stochastic process captured by the Master equation are thus obtained by the MC method, thereby enabling the calculation of observables such as the $\mathrm{CO}$ coverage or the size distribution of Pd surface clusters.

For all simulations, the Pd loading of the PdAu surface was $2 \%$ atomic ratio on a lattice with a total number of 2500 metal atoms. The total number of sites was 14,700 , including top and hollow (i.e., bridge or threefold) site types (Supplementary Fig. S10). The threefold sites represented both fcc and hcp hollow sites. The adsorption of $\mathrm{CO}$ on mixed metal sites (i.e., bridge sites between an $\mathrm{Au}$ and a Pd atom and threefold sites surrounded by both $\mathrm{Pd}$ ad $\mathrm{Au}$ sites) is not stable. Accordingly, these configurations are assigned with a large energetic contribution to the total energy, thereby assuring their instability in our MC simulations ${ }^{43}$. To replicate the CO-DRIFTS conditions, our MC simulations were performed at $\mathrm{P}_{\mathrm{CO}}=0.1 \mathrm{bar}$, and at various temperatures within the range of $30-70^{\circ} \mathrm{C}$. The $\mathrm{CO}$ dopant fractional coverage was calculated as follows:

$$
\Omega_{\mathrm{CO}}=\frac{N_{\mathrm{CO}}}{N_{\mathrm{Pd}}},
$$

where $N_{\mathrm{CO}} *$ is the number of $\mathrm{CO}$ molecules adsorbed on Pd sites, and $N_{\mathrm{Pd}}$ is the total number of Pd atoms on the lattice.

The lattice energetics were predicted by a cluster expansion (CE), which was fitted based on a DFT dataset ${ }^{43}$. This CE was assessed by the leave-one-out crossvalidation score, which was found equal to $3.0 \mathrm{meV} / \mathrm{site}^{43}$. For the interested reader, more information on the fitting and performance of the CE can be found elsewhere ${ }^{43}$. During the simulation, several state-to-state steps could happen, including atomic swaps between $\mathrm{Au}$ and $\mathrm{Pd}$ atoms, $\mathrm{CO}$ diffusion from site-to-site, and $\mathrm{CO}$ adsorption/desorption. The full list of the microscopic processes that can take place on the MC lattice is presented in the Supporting Information. Our calculations aimed at sampling the surface configurations that show the highest thermodynamic stability and did not account for kinetic effects related to $\mathrm{Au} / \mathrm{Pd}$ atomic swaps. The average fractions of surface Pd species (i.e., Pd monomers and Pd aggregates) were computed from Eq. (8) after reaching stationary conditions. For the latter, we checked that the $\mathrm{CO}$ coverage and the average fractions of the surface Pd species $\left(\bar{Y}_{k}\right)$ remain approximately constant with respect to the simulation time.

$$
\bar{Y}_{k}=\frac{1}{N_{\mathrm{MC}, \text { conf }}} \sum_{i=1}^{N_{\mathrm{MC}, \text { conf }}} Y_{k, i}=\frac{1}{N_{\mathrm{MC}, \text { conf }}} \sum_{i=1}^{N_{\mathrm{MCc} \text { conf }}}\left(\frac{N_{k, i}}{N_{\mathrm{tot}, i}}\right), k \in\{\text { Pdmonomers, Pdaggregates }\},
$$

where $\bar{Y}_{k, i}$ is the fraction of dopant species $k$ in snapshot $i, N_{\mathrm{MC} \text {,conf }}$ is the number of lattice snapshots taken under stationary conditions, $N_{k, i}$ is the number of dopant species $k$ in snapshot $i$ and $N_{\mathrm{tot}, i}$ is the total number of species detected in snapshot $i$.

\section{Data availability}

The data that support the plots within this paper and other findings of this study are available from the corresponding author upon reasonable request.

\section{Code availability}

The codes that support the findings of this study are available from the corresponding author upon reasonable request.

Received: 15 August 2020; Accepted: 28 January 2021; Published online: 09 March 2021

\section{References}

1. Ni, M., Leung, D. Y. C. \& Leung, M. K. H. A review on reforming bio-ethanol for hydrogen production. Int. J. Hydrog. Energy 32, 3238-3247 (2007).

2. Wang, C., Ouyang, M., Li, M., Lee, S. \& Flytzani-Stephanopoulos, M. Lowcoordinated Pd catalysts supported on $\mathrm{Zn}_{1} \mathrm{Zr}_{1} \mathrm{O}_{\mathrm{x}}$ composite oxides for selective methanol steam reforming. Appl. Catal. A-Gen. 580, 81-92 (2019).

3. Pérez-Temprano, M. H., Casares, J. A. \& Espinet, P. Bimetallic catalysis using transition and group 11 metals: an emerging tool for $\mathrm{C}-\mathrm{C}$ coupling and other reactions. Chem. Eur. J. 18, 1864-1884 (2012).

4. Garin, F. Environmental catalysis. Catal. Today 89, 255-268 (2004).

5. Nutt, M. O., Hughes, J. B. \& Wong, M. S. Designing Pd-on-Au bimetallic nanoparticle catalysts for trichloroethene hydrodechlorination. Environ. Sci. Technol. 39, 1346-1353 (2005).

6. Enache, D. I. et al. Solvent-free oxidation of primary alcohols to aldehydes using $\mathrm{Au}-\mathrm{Pd} / \mathrm{TiO}_{2}$ catalysts. Science 311, 362 (2006).

7. Yin, Y. B. et al. PdAu-catalyzed oxidation through in situ generated $\mathrm{H}_{2} \mathrm{O}_{2}$ in simulated produced water. Catal. Today 339, 362-370 (2020).

8. Sachtler, J. W. A. \& Somorjai, G. A. Influence of ensemble size on CO chemisorption and catalytic n-hexane conversion by $\mathrm{Au}-\mathrm{Pt}(111)$ bimetallic single-crystal surfaces. J. Catal. 81, 77-94 (1983).

9. Li, H., Guo, S., Shin, K., Wong, M. S. \& Henkelman, G. Design of a Pd-Au nitrite reduction catalyst by identifying and optimizing active ensembles. ACS Catal. 9, 7957-7966 (2019).

10. Wrasman, C. J. et al. Synthesis of colloidal Pd/Au dilute alloy nanocrystals and their potential for selective catalytic oxidations. J. Am. Chem. Soc. 40, 12930-12939 (2018)

11. Tierney, H. L., Baber, A. E. \& Sykes, E. C. H. Atomic-scale imaging and electronic structure determination of catalytic sites on $\mathrm{Pd} / \mathrm{Cu}$ near surface alloys. J. Phys. Chem. C. 113, 7246-7250 (2009).

12. Hannagan, R. T., Giannakakis, G., Flytzani-Stephanopoulos, M. \& Sykes, E. C H. Single-atom alloy catalysis. Chem. Rev. 120, 12044-12088 (2020).

13. Darby, M. T., Stamatakis, M., Michaelides, A. \& Sykes, E. C. H. Lonely atoms with special gifts: breaking linear scaling relationships in heterogeneous catalysis with single-atom alloys. J. Phys. Chem. Lett. 9, 5636-5646 (2018).

14. Marcinkowski, M. D. et al. $\mathrm{Pt} / \mathrm{Cu}$ single-atom alloys as coke-resistant catalysts for efficient C-H activation. Nat. Chem. 10, 325-332 (2018).

15. Lucci, F. R. et al. Selective hydrogenation of 1,3-butadiene on platinum-copper alloys at the single-atom limit. Nat. Commun. 6, 1-8 (2015).

16. Lucci, F. R. et al. The effect of single pd atoms on the energetics of recombinative $\mathrm{O}_{2}$ desorption from $\mathrm{Au}(111)$. Surf. Sci. 677, 296-300 (2018).

17. Gao, F., Wang, Y. \& Goodman, D. W. CO oxidation over AuPd(100) from ultrahigh vacuum to near-atmospheric pressures: the critical role of contiguous Pd atoms. J. Am. Chem. Soc. 131, 5734-5735 (2009).

18. Goodman, E. D. et al. Supported catalyst deactivation by decomposition into single atoms is suppressed by increasing metal loading. Nat. Catal. 2, 748-755 (2019).

19. Schay, Z. \& Tétényi, P. Catalysis by highly diluted $\mathrm{Ni}+\mathrm{Cu}$ alloy foils: $\mathrm{H}_{2}-\mathrm{D}_{2}$ equilibration and ethylene-deuterium exchange reaction. J. Chem. Soc. Faraday Trans. 75, 1001-1010 (1979).

20. Shan, J. et al. NiCu single atom alloys catalyze the $\mathrm{C}-\mathrm{H}$ bond activation in the selective non-oxidative ethanol dehydrogenation reaction. Appl. Catal. BEnviron. 226, 534-543 (2018).

21. Giannakakis, G. et al. NiAu single atom alloys for the non-oxidative dehydrogenation of ethanol to acetaldehyde and hydrogen. Top. Catal. 61, 475-486 (2018).

22. Rostrup-Nielsen, J. R. \& Alstrup, I. Innovation and science in the process industry: steam reforming and hydrogenolysis. Catal. Today 53, 311-316 (1999).

23. $\mathrm{Wu}, \mathrm{C}$. H. et al. Bimetallic synergy in cobalt-palladium nanocatalysts for $\mathrm{CO}$ oxidation. Nat. Catal. 2, 78-85 (2018).

24. Tao, F. et al. Reaction-driven restructuring of Rh-Pd and Pt-Pd core-shell nanoparticles. Science 322, 932-934 (2008).

25. Gibson, E. K. et al. Restructuring of AuPd nanoparticles studied by a combined XAFS/DRIFTS approach. Chem. Mater. 27, 3714-3720 (2015).

26. van Spronsen, M. A. et al. The dynamics of surface alloys: rearrangement of $\mathrm{Pd} / \mathrm{Ag}(111)$ induced by $\mathrm{CO}$ and $\mathrm{O}_{2}$. J. Phys. Chem. C. 123, 8312-8323 (2019).

27. Bliem, R. et al. Dual role of $\mathrm{CO}$ in the stability of subnano Pt clusters at the $\mathrm{Fe}_{3} \mathrm{O}_{4}$ (001) surface. Proc. Natl Acad. Sci. USA 113, 8921-8926 (2016).

28. Mamatkulov, M. et al. Pd segregation on the surface of bimetallic PdAu nanoparticles induced by low coverage of adsorbed CO. J. Phys. Chem. C. 123, 8037-8046 (2018)

29. Boubnov, A. et al. Insight into restructuring of Pd-Au nanoparticles using EXAFS. Radiat. Phys. Chem. 175, 108304 (2020).

30. McCue, A. J. \& Anderson, J. A. CO induced surface segregation as a means of improving surface composition and enhancing performance of $\mathrm{CuPd}$ bimetallic catalysts. J. Catal. 329, 538-546 (2015).

31. Gao, F., Wang, Y. \& Goodman, D. W. CO oxidation over AuPd(100) from ultrahigh vacuum to near-atmospheric pressures: $\mathrm{CO}$ adsorption-induced 
surface segregation and reaction kinetics. J. Phys. Chem. C. 113, 14993-15000 (2009).

32. Giannakakis, G., Flytzani-Stephanopoulos, M. \& Sykes, E. C. H. Single-atom alloys as a reductionist approach to the rational design of heterogeneous catalysts. Acc. Chem. Res. 52, 237-247 (2019).

33. Soto-Verdugo, V. \& Metiu, H. Segregation at the surface of an Au/Pd alloy exposed to CO. Surf. Sci. 601, 5332-5339 (2007).

34. An, H., Ha, H., Yoo, M. \& Kim, H. Y. Understanding the atomic-level process of CO-adsorption-driven surface segregation of Pd in (AuPd)147 bimetallic nanoparticles. Nanoscale 9, 12077-12086 (2017).

35. García-Mota, M. \& López, N. Temperature and pressure effects in CO titration of ensembles in PdAu(111) alloys using first principles. Phys. Rev. B 82, 075411 (2010).

36. Ham, H. C. et al. Role of small Pd ensembles in boosting $\mathrm{CO}$ oxidation in AuPd alloys. J. Phys. Chem. Lett. 3, 566-570 (2012).

37. Meng, J., Zhu, B. \& Gao, Y. Surface composition evolution of bimetallic alloys under reaction conditions. J. Phys. Chem. C. 123, 28241-28247 (2019).

38. Zhu, B. et al. Reshaping of metal nanoparticles under reaction conditions. Angew. Chem. Int. Ed. 59, 2171-2180 (2020).

39. Kim, H. Y. \& Henkelman, G. CO adsorption-driven surface segregation of Pd on $\mathrm{Au} / \mathrm{Pd}$ bimetallic surfaces: role of defects and effect on $\mathrm{CO}$ oxidation. ACS Catal. 3, 2541-2546 (2013).

40. Lu, Z., Yadav, S. \& Singh, C. V. Predicting aggregation energy for single atom bimetallic catalysts on clean and $\mathrm{O}^{*}$ adsorbed surfaces through machine learning models. Catal. Sci. Technol. 10, 86-98 (2020).

41. Wang, Q. et al. Atomic origin of CO-Interaction effect of PtPb@Pt catalyst revealed by in situ environmental transmission electron microscopy. Nano Energy 76, 105099 (2020).

42. Darby, M. T., Sykes, E. C. H., Michaelides, A. \& Stamatakis, M. Carbon monoxide poisoning resistance and structural stability of single atom alloys. Top. Catal. 61, 428-438 (2018)

43. Papanikolaou, K. G., Darby, M. T. \& Stamatakis, M. Engineering the surface architecture of highly dilute alloys: an ab initio Monte-Carlo approach. ACS Catal. 10, 1224-1236 (2020).

44. Papanikolaou, K. G., Darby, M. T. \& Stamatakis, M. CO-induced aggregation and segregation of highly dilute alloys: a density functional theory study. $J$. Phys. Chem. C. 123, 9128-9138 (2019).

45. Mezey, L. Z. \& Giber, J. The surface free energies of solid chemical elements: calculation from internal free enthalpies of atomization. Jpn. J. Appl. Phys. 21, 1569-1571 (1982).

46. Tyson, W. R. \& Miller, W. A. Surface free energies of solid metals: estimation from liquid surface tension measurements. Surf. Sci. 62, 267-276 (1977).

47. Engel, T. \& Ertl, G. Characterization of oxide surfaces and zeolites by carbon monoxide as an IR probe molecule. Adv. Catal. 28, 1-78 (2002).

48. Toyoshima, R. et al. CO adsorption on Pd-Au alloy surface: reversible adsorption site switching induced by high-pressure CO. J. Phys. Chem. C. 120, 416-421 (2015).

49. Hammer, B. \& Norskov, J. K. Why gold is the noblest of all the metals. Nature 376, 238-240 (1995).

50. Peterson, A. A. \& Nørskov, J. K. Activity descriptors for $\mathrm{CO}_{2}$ electroreduction to methane on transition-metal catalysts. J. Phys. Chem. Lett. 3, 251-258 (2012).

51. Papanikolaou, K. G. \& Stamatakis, M. On the behaviour of structure-sensitive reactions on single atom and dilute alloy surfaces. Catal. Sci. Technol. 10, 5815-5828 (2020).

52. Liu, J. et al. Integrated catalysis-surface science-theory approach to understand selectivity in the hydrogenation of 1-hexyne to 1-hexene on PdAu single-atom alloy catalysts. ACS Catal. 9, 8757-8765 (2019).

53. Liu, J. et al. Palladium-gold single atom alloy catalysts for liquid phase selective hydrogenation of 1-hexyne. Catal. Sci. Technol. 7, 4276-4284 (2017).

54. Luneau, M. et al. Enhancing catalytic performance of dilute metal alloy nanomaterials. Commun. Chem. 3, 46 (2020).

55. Hadjiivanov, K. I. \& Vayssilov, G. N. Characterization of oxide surfaces and zeolites by carbon monoxide as an IR probe molecule. Adv. Catal. 47, 307-511 (2002).

56. Wei, T., Wang, J. \& Goodman, D. W. Characterization and chemical properties of $\mathrm{Pd}-\mathrm{Au}$ alloy surfaces†. J. Phys. Chem. C. 111, 8781-8788 (2007).

57. Ward, T. et al. Effects of Pd on catalysis by Au: $\mathrm{CO}$ adsorption, $\mathrm{CO}$ oxidation, and cyclohexene hydrogenation by supported $\mathrm{Au}$ and $\mathrm{Pd}-\mathrm{Au}$ catalysts. ACS Catal. 3, 2644-2653 (2013).

58. Hanrieder, E. K., Jentys, A. \& Lercher, J. A. Atomistic engineering of catalyst precursors: dynamic reordering of PdAu nanoparticles during vinyl acetate synthesis enhanced by potassium acetate. ACS Catal. 5, 5776-5786 (2015).

59. Oxford, S. M. et al. Study of supported PtCu and PdAu bimetallic nanoparticles using in-situ X-ray tools. J. Phys. Chem. C. 114, 17085-17091 (2010).
60. Crossley, A. \& King, D. A. Infrared spectra for co isotopes chemisorbed on Pt "111": evidence for strong absorbate coupling interactions. Surf. Sci. 68, 528-538 (1977).

61. Lamberti, C., Zecchina, A., Groppo, E. \& Bordiga, S. Probing the surfaces of heterogeneous catalysts by in situ IR spectroscopy. Chem. Soc. Rev. 39, 4951-5001 (2010).

62. Zhu, B. et al. Evidence of Pd segregation and stabilization at edges of AuPd nano-clusters in the presence of CO: a combined DFT and DRIFTS study. J. Catal. 308, 272-281 (2013)

63. Wrigley, J. D. \& Ehrlich, G. Surface diffusion by an atomic exchange mechanism. J. Phys. Chem. 44, 661-663 (1980).

64. Hansen, L., Stoltze, P., Jacobsen, K. W. \& Nørskov, J. K. Self-diffusion on copper surfaces. Phys. Rev. B 44, 6523-6526 (1991)

65. Kellogg, G. L. Field ion microscope studies of single-atom surface diffusion and cluster nucleation on metal surfaces. Surf. Sci. Rep. 21, 1-88 (1994).

66. Vannice, M. A. \& Wang, S. Y. Determination of IR extinction coefficients for linear- and bridged-bonded carbon monoxide on supported palladium. J. Phys. Chem. 85, 2543-2546 (1981).

67. Zhu, B., Meng, J. \& Gao, Y. Equilibrium shape of metal nanoparticles under reactive gas conditions. J. Phys. Chem. C. 121, 5629-5634 (2017).

68. Lazić, P. et al. Density functional theory with nonlocal correlation: a key to the solution of the CO adsorption puzzle. Phys. Rev. B 81, 045401 (2010).

69. Janthon, P., Viñes, F., Sirijaraensre, J., Limtrakul, J. \& Illas, F. Adding pieces to the CO/Pt(111) puzzle: the role of dispersion. J. Phys. Chem. C. 121, 3970-3977 (2017).

70. Feibelman, P. J. et al. The CO/Pt(111) puzzle. J. Phys. Chem. B 105, 4018-4025 (2001).

71. Gautier, S., Steinmann, S. N., Michel, C., Fleurat-Lessard, P. \& Sautet, P. Molecular adsorption at $\mathrm{Pt}(111)$. How accurate are DFT functionals? Phys. Chem. Chem. Phys. 17, 28921-28930 (2015).

72. Shan, J. et al. Selective non-oxidative dehydrogenation of ethanol to acetaldehyde and hydrogen on highly dilute $\mathrm{NiCu}$ alloys. Appl. Catal. BEnviron. 205, 541-550 (2017)

73. Ouyang, M., Cao, S., Yang, S., Li, M. \& Flytzani-Stephanopoulos, M. Atomically dispersed Pd supported on zinc oxide for selective nonoxidative ethanol dehydrogenation. Ind. Eng. Chem. Res. 59, 2648-2656 (2020).

74. Evans, E. J. et al. Mechanistic insights on ethanol dehydrogenation on Pd-Au model catalysts: a combined experimental and DFT study. Phys. Chem. Chem. Phys. 19, 30578-30589 (2017).

75. Li, H. \& Henkelman, G. Dehydrogenation selectivity of ethanol on closepacked transition metal surfaces: a computational study of monometallic, $\mathrm{Pd} /$ $\mathrm{Au}$, and $\mathrm{Rh} / \mathrm{Au}$ catalysts. J. Phys. Chem. C. 121, 27504-27510 (2017).

76. Guan, Y. \& Hensen, E. J. M. Ethanol dehydrogenation by gold catalysts: the effect of the gold particle size and the presence of oxygen. Appl. Catal. A-Gen. 361, 49-56 (2009)

77. Nadeem, M. A., Majeed, I., Waterhouse, G. I. N. \& Idriss, H. Study of ethanol reactions on $\mathrm{H}_{2}$ reduced $\mathrm{Au} / \mathrm{TiO}_{2}$ anatase and rutile: effect of metal loading on reaction selectivity. Catal. Struct. React. 1, 61-70 (2015).

78. Kresse, G. \& Hafner, J. Ab initio molecular dynamics for liquid metals. Phys Rev. B 47, 558-561 (1993).

79. Kresse, G. \& Furthmüller, J. Efficiency of ab-initio total energy calculations for metals and semiconductors using a plane-wave basis set. Comput. Mater. Sci. 6, 15-50 (1996).

80. Hammer, B., Hansen, L. B. \& Nørskov, J. K. Improved adsorption energetics within density-functional theory using revised Perdew-Burke-Ernzerhof functionals. Phy. Rev. B 59, 7413-7421 (1999).

81. Perdew, J. P., Burke, K. \& Ernzerhof, M. Generalized gradient approximation made simple. Phys. Rev. Lett. 77, 3865-3868 (1996).

82. Blöchl, P. E. Projector augmented-wave method. Phys. Rev. B 50, 17953-17979 (1994).

83. Darby, M. T., Réocreux, R., Sykes, E. C. H., Michaelides, A. \& Stamatakis, M. Elucidating the stability and reactivity of surface intermediates on single-atom alloy catalysts. ACS Catal. 8, 5038-5050 (2018).

84. Stamatakis, M. Zacros: advanced lattice-KMC simulation made easy. Software code available from http://zacros.org/.

85. Savva, G. D. \& Stamatakis, M. Comparison of queueing data-structures for kinetic Monte Carlo simulations of heterogeneous catalysts. J. Phys. Chem. A 124, 7843-7856 (2020).

86. Ravipati, S., d'Avezac, M., Nielsen, J., Hetherington, J. \& Stamatakis, M. A caching scheme to accelerate kinetic Monte Carlo simulations of catalytic reactions. J. Phys. Chem. A 124, 7140-7154 (2020).

87. Nielsen, J., d'Avezac, M., Hetherington, J. \& Stamatakis, M. Parallel kinetic Monte Carlo simulation framework incorporating accurate models of adsorbate lateral interactions. J. Chem. Phys. 139, 224706 (2013).

88. Stamatakis, M. \& Vlachos, D. G. A graph-theoretical kinetic Monte Carlo framework for on-lattice chemical kinetics. J. Chem. Phys. 134, 214115 (2011).

89. Stamatakis, M. Kinetic modelling of heterogeneous catalytic systems. J. Phys. Condens. Matter 27, 013001 (2015). 
90. Stamatakis, M. \& Vlachos, D. G. Unraveling the complexity of catalytic reactions via kinetic Monte Carlo simulation: current status and frontiers. ACS Catal. 2, 2648-2663 (2012).

91. Papanikolaou, K. G. \& Stamatakis, M. Computational modelling of nanomaterials. Front. Nanosci. 17, 95-125 (2020).

\section{Acknowledgements}

M.O. thanks the Department of Chemical and Biological Engineering at Tufts University for support. K.G.P. and M.S. acknowledge support from the Department of Chemical Engineering at University College London. E.C.H.S. thanks the Division of Chemical Sciences, Office of Basic Energy Sciences, CPIMS Program, U.S. Department of Energy, under Grant No. DE-SC0004738. G.G. was supported in part by the Integrated Mesoscale Architectures for Sustainable Catalysis, an Energy Frontier Research Center funded by the U.S. Department of Energy, Office of Science, Basic Energy Sciences under award \#DE-SC0012573. Part of this work was also performed at Stanford Synchrotron Radiation Lightsource (SSRL) of SLAC National Accelerator Laboratory and use of the SSRL is supported by the U.S. Department of Energy, Office of Science, Office of Basic Energy Sciences under Contract No. DE-AC02-76SF00515 and by Co-ACCESS supported by the U.S. Department of Energy, Office of Basic Energy Sciences, Chemical Sciences, Geosciences, and Biosciences Division. The authors gratefully acknowledge the use of the UCL High-Performance Computing Facility Myriad@UCL in the completion of the simulations of this work. The authors acknowledge Arun Asundi for collecting the XPS data. The authors acknowledge Dr. Jules Gardener for taking the STEM images at the Harvard CNS center.

\section{Author contributions}

M.O., M.F.-S., and E.C.H.S. designed the experiments and analyzed the data. M.O. synthesized the sample and performed most of the experimental studies. A.B., A.S.H., S.R.B., and G.G. carried out the XAS experiment. M.O., A.B., A.S.H., and S.R.B. performed XAFS analysis. K.G.P. and M.S. carried out computational studies. All authors discussed the results and edited the paper.

\section{Competing interests}

The authors declare no competing interests.

\section{Additional information}

Supplementary information The online version contains supplementary material available at https://doi.org/10.1038/s41467-021-21555-z.

Correspondence and requests for materials should be addressed to E.C.H.S

Peer review information Nature Communications thanks Shinya Furukawa, Xin Zhang and the other, anonymous, reviewer(s) for their contribution to the peer review of this work.

Reprints and permission information is available at http://www.nature.com/reprints

Publisher's note Springer Nature remains neutral with regard to jurisdictional claims in published maps and institutional affiliations.

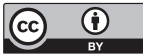

Open Access This article is licensed under a Creative Commons Attribution 4.0 International License, which permits use, sharing, adaptation, distribution and reproduction in any medium or format, as long as you give appropriate credit to the original author(s) and the source, provide a link to the Creative Commons license, and indicate if changes were made. The images or other third party material in this article are included in the article's Creative Commons license, unless indicated otherwise in a credit line to the material. If material is not included in the article's Creative Commons license and your intended use is not permitted by statutory regulation or exceeds the permitted use, you will need to obtain permission directly from the copyright holder. To view a copy of this license, visit http://creativecommons.org/ licenses/by/4.0/.

(C) The Author(s) 2021 